\title{
Time and mode of Culicidae evolutionary history
}

Alexandre Freitas da Silva ${ }^{1,2}$, Laís Ceschini Machado ${ }^{1,2}$, Marcia Bicudo de Paula ${ }^{3}$, Carla Júlia da Silva Pessoa Vieira, Roberta Vieira de Morais Bronzoni ${ }^{4}$, Maria Alice Varjal de Melo Santos ${ }^{1,2}$, Gabriel Luz Wallau ${ }^{1,2, *}$

${ }^{1}$ Programa de Pós-Graduação em Biociências e Biotecnologia em Saúde, ${ }^{2}$ Departamento de Entomologia, Fundação Oswaldo Cruz - Instituto Aggeu Magalhães, Recife, Pernambuco, Brasil, ${ }^{3}$ Universidade de São Paulo, Faculdade de Saúde Pública, São Paulo, São Paulo, Brasil, ${ }^{4}$ Universidade Federal do Mato Grosso, Sinop, Mato Grosso, Brasil. *Corresponding author. 


\begin{abstract}
Mosquitoes are insects of medical importance due their role as vectors of different pathogens to humans and other mammals. There is a lack of information about the evolutionary history and phylogenetic positioning of the majority of mosquitoes species. Here we sequenced the mitogenomes of mosquitoes species through low-coverage sequencing and data mining. A total of 37 draft mitogenomes were assembled representing 11 genera and 16 of those were sequenced for the first time. The recovered mitogenomes showed a coverage breadth average of $81.24 \%$. Most of the species were clustered in monophyletic clades with other members of their own genus with exception of the Aedini tribe which was paraphyletic corroborating other findings. We established for the first time the monophyletic status of eight species from the tribe Mansoniini including both Coquillettidia and Mansonia genus and established the basal positioning of Aedeomyiini and Uranotaeniini tribes regarding the Culicinae subfamily. Molecular clock dated the Culicidae family emergence around 273 MYA and the split between Anophelinae and Culicinae subfamily around 182 MYA in the Jurassic period. Low-coverage sequencing is effective to recover mitogenomes, establish phylogenetic knowledge generating basic fundamental information to the understanding of the role of these species as pathogen vectors.
\end{abstract}




\section{Introduction}

Mosquitoes compose a larger group of insects from the Culicidae family. There are around 3,567 valid species classified into two subfamilies (Anophelinae and Culicinae) and 41 genera (http://mosquito-taxonomic-inventory.info/ accessed on 21 Oct., 2019). The large majority of mosquitoes species have an atropofilic behaviour towards reptiles and mammals including humans ${ }^{1}$. Because of that they can transmit many pathogens such bacteria ${ }^{2}$, malaria protozoa (OMS, 2018), filarial worms ${ }^{3}$ and arboviruses ${ }^{4}$. Mosquitoes are responsible for the transmission of pathogens that cause outbreaks and epidemics annually in the tropical region, but the current globalization process and land use change are rising human-mosquito contact allowing the emergence of new mosquito-borne disease ${ }^{5-7}$. Several of the new emerging pathogens arose from forested environments where they circulate in a sylvatic cycle between wild animals and arthropod vectors species such as mosquitos ${ }^{8}$. Although there are abundant evidence that spillover occurs from sylvatic to urban environments, we know very little about the sylvatic cycle of these pathogens including the vector species that transmit them in their natural environment ${ }^{9}$. Therefore, basic knowledge about vector evolution and ecology is highly needed to better understand their role in the transmission cycle of pathogens ${ }^{5,10,11}$.

The huge improvement in nucleic acid sequencing platforms in the last decade has allowed an explosion of genomic information from a wide range of species. Mitogenomes, the entire mitochondrial genome, have been widely used as a target molecule to elucidate different aspects of metazoa species evolution such as population dynamics and phylogenetic relationships 12. Complete mitogenomes are reliable tools to be used as a molecular marker in ecological and evolutionary studies because they provide genes with different evolutionary rates such as the most conserved rRNA genes (12S and 16S), the intermediate ND1-6 genes and the fast evolving Cytochrome oxidase subunit I (COI) gene, the most used molecular marker for species identification, allowing an accurate establishment of both ancient and recent speciation events 13-15. In addition, mitogenomes have a uniparental heritage, high copy number per cells and single-copy genes which facilitates DNA recovery and phylogenetic analysis ${ }^{16-18}$. Recently, some studies have sequenced a larger number of mitochondrial genomes from different mosquito species, but they are mostly focused on Anopheles species ${ }^{19-21}$. Mosquito mitogenomes are structurally conserved following the metazoa gene number and order, with few exceptions, showing 37 genes comprising 13 protein coding genes, 22 tRNAs and 2 rRNA genes ${ }^{22-24}$. Its size range varies from $14.820 \mathrm{bp}$ for An. maculatus to $16.790 \mathrm{bp}$ for Ae. aegypti (NCBI, https://www.ncbi.nlm.nih.gov/genome/browse\#!/organelles/culicidae accessed on 21 oct., 2019).

Mitogenome sequencing has been a hard task using the first generation of sequence platforms based on the Sanger method. The first mosquito mitogenome have been obtained after laborious steps such as mitochondria purification followed by DNA extraction, cloning and Sanger sequencing of several fragments ${ }^{25,26}$. Today there are a number of alternative approaches available to obtain mitogenomes which was only possible due to the improvement of second and 
third generation of sequencing platforms. Most of these strategies are based on PCR/Long Range PCR coupled with Next-generation sequencing (NGS), shotgun Whole Genome Sequencing or mitogenome sequencing through RNA-Seq data ${ }^{27,28}$. Other approaches available allow the recovery of mitogenomes by PCR amplification from environment samples and pooled DNA and mitogenome recovery from low-coverage sequencing ${ }^{29-31}$. Moreover, a number of bioinformatics tools were developed to specifically assembly and annotate mitogenomes ${ }^{32-36}$

Most of the available mitogenomes belong to Anopheles species with much fewer genomes from Culex, Aedes and other genera such as Haemagogus, Bironella, Sabethes, and Lutzia $^{19-21,24,37}$, but there is no available molecular data for the large majority of the species. Aiming to contribute with this basic and fundamental knowledge we performed low-coverage sequencing and data mining on already published Culicidae SRA data in order to characterize the mitogenomes from different species and genera and better understand the evolutionary history of mosquitoes focusing in Culicinae subfamily. Overall, we reconstructed and positioned 37 mitogenomes, 35 of them for the first time, representing 11 genera and performed molecular dating of speciation time of all common ancestors.

\section{Material and methods}

\section{Mosquito sampling and taxonomic identification}

Mosquito samples were collected in remnants of the brazilian Atlantic forest and from the South border of the Amazonian forest Brazil. Three locations were sampled at Pernambuco state, Parque Estadual Dois Irmãos ( $\left.8^{\circ} 00^{\prime} 43.3^{\prime \prime} \mathrm{S} 34^{\circ} 56^{\prime} 40.7^{\prime \prime} \mathrm{W}\right)$ at the Recife municipality; Reserva Ecológica de Carnijó ( $\left.8^{\circ} 08^{\prime} 20.7^{\prime \prime S} 35^{\circ} 04^{\prime} 47.3^{\prime \prime W}\right)$ at Moreno municipality; and Aldeia at Camaragibe municipality. Additionally, one sampling was performed at Sinop municipality, Mato Grosso state. Different sampling methods were employed aiming to collect a large diversity of species. Diurnal sampling was performed with aspirators (Horst model) and entomological nets, larvae and pupae were collected on water pools and plant holes. Nocturnal sampling was performed using CDC-light traps and BG-Sentinel were used to sample mosquitoes attracted by light and odorants. The specimens were transported alive to the Entomology department of Aggeu Magalhães Institute - Oswaldo Cruz Foundation (IAM/FIOCRUZ), immature specimens were maintained in liquid water and feed with cat food (Friskies ${ }^{\circledR}$ ) until the emergence of adults. Adults mosquitoes were separated per morphological groups, were dry stored in silica at room temperature until taxonomic identification. Taxonomic keys for neotropical Culicidae were used for species identification ${ }^{38,39}$. Besides the collection performed in this work we included Aedes taeniorhynchus and Aedes scapularis samples ceded by collaborators of the Entomology department of IAM sampled respectively at São Luis 
municipality, Maranhão state and Juazeiro municipality, Bahia state. All collections were authorized by the regulatory organ - SISBIO under the license number: 58716-1.

\section{DNA extraction and sequencing}

The specimens were macerated in ultrapure water using 40ul/individual in single or pooled samples (Supplementary table 1) according to the number of specimens collected per species. Both male and female individuals and samples from different collection points were included in the pools. Total DNA extraction were performed using ethanol precipitation method ${ }^{40}$ and QIAprep Spin Miniprep extraction (QIAGEN) in order to improve mitochondrial DNA by enrichment as suggested by Quispe-Tintaya et al. (2013). All samples were assessed by quality and purity with NanoDrop 2000 (Thermo Scientific) and quantified through Qubit ${ }^{\circledR}$ dsDNA HS (High Sensitivity Assay) kit. The DNA library was prepared using the Nextera XT library preparation kit following the recommendations of the manufacturer (Illumina, San Diego, CA, USA). DNA library was sequenced on the Illumina Miseq platform using a paired-end approach of 75 bases with Reagent Kit V3 of 150 cycles.

\section{Dataset construction}

A search on National Center for Biotechnology Information (NCBI) was performed to recovery already characterized mitochondrial genomes (mitogenomes) from mosquitoes representing different genus (Supplementary table 2). Besides, we also searched on the SRA database for mosquitoes raw sequence reads (Whole genome sequencing and RNA-Seq) available up to November of 2018 representing species that had no mitogenome available at the time (Supplementary table 3).

\section{Quality control of sequences}

The raw reads (sequenced in this study and recovered from SRA) were checked for quality using FastQC program (http://www.bioinformatics.babraham.ac.uk/projects/fastqc/) and results were summarized on MultiQC tool ${ }^{41}$. Based on the excellent quality of our sequenced raw reads they were not trimmed (Supplementary figure 1) but, all SRA libraries were trimmed using the Trimmomatic tool $v 0.35^{42}$ to remove adapters and ensure that the quality of sequences (Phred score $>20$ ).

\section{Mitogenome assembly and annotation}

The mitogenomes were assembled using a baiting and iterative mapping approach implemented in MITObim $1.9^{34}$. Different mosquito mitogenome were used as reference 
genome for the first capturing of reads considering the closest mitogenome available to each species analysed. SRA reads were assembled using MITObim default parameters (-kbait parameter $=31$ ). While we used a combination of parameters to generate a consensus sequence for the sequenced species. A first assembly was performed with $-k$ bait $=15$ followed by a second assembly step using $-k$ bait $=31$. The final consensus assembly was composed by the consensus of the two assemblies that was then checked with well characterized mitogenomes to correct any potential assembly errors (ex. the assembly of non alignable regions between mitogenomes). To assess the average coverage depth of each mitogenome, the reads were mapped against the assembled mitogenomes through the MIRAbait module from MIRA sequence assembler software 43. Automatic gene annotation were performed on MITOS2 web server (available on http://mitos2.bioinf.uni-leipzig.de/index.py) ${ }^{35}$ based on invertebrate genetic code against the metazoan Refseq 81. Comparative genomics maps were built using Ae. aegypti mitogenome (Accession number: NC_010241.1) as reference in BRIG (BLAST Ring Image Generator) ${ }^{44}$.

\section{Evolutionary analysis}

Nucleotide mitogenomes sequences characterized here, were aligned by MAFFT v 7.0 tool ${ }^{45}$ with already characterized mitogenomes recovered from databases (Supplementary table 2). The non aligned sites were removed using GBLOCKS tool v. $0.91 \mathrm{~b}$ - default parameters, with exception for the allowed gap positions that was set as with the "half" option ${ }^{46}$ and final alignment was visualized on Aliview ${ }^{47}$. The evolutionary analysis were performed based on four possible alignment approaches: I) Complete nucleotide mitogenome alignment sequences, II) Partitioned nucleotide sequence of protein coding genes, III) Partitioned predicted amino acid sequences from coding regions and IV) Concatenated alignment of amino acid sequences. Nucleotide substitution saturation analysis was performed for each nucleotide gene alignment in DAMBE software ${ }^{48}$ evaluating 1 st +2 nd and 3 rd codon position separately through the Xia et al. test ${ }^{49}$. Nucleotide substitution models for I and II alignments were obtained with Smart model selection (SMS) implemented on PhyML webserver ${ }^{50}$. Protein evolutionary models were assessed for III and IV alignments using Prottest 3.4.2 ${ }^{51}$. All phylogenetic analysis were based on a Bayesian Markov Monte Carlo approach (MCMC) performed on BEAST 1.8.4 package ${ }^{52}$ in order to infer the topology of Culicidae family and the speciation time of the common ancestor of clades in million years. In order to obtain calibration points for the molecular clock analysis, we performed a literature search to obtain fossil dates representing the different Culicidae clades. Although there are several potential calibration points to the Culicidae tree we only kept the ones supported by fossil evidence. We used four calibration points representing the Diptera order, Culicidae family, Anophelinae and Culicinae subfamily (Supplementary table 4).

Bayesian analysis was performed with at least three independent runs of 150 million generations sampling at each 1000 trees, for each alignment dataset. The lineage through time analysis and Effective sample size (ESS) were evaluated by Tracer $1.7 .1^{53}$ and reached 200 for 
most of the important parameters for dating and tree likelihood. The analysis were performed under an uncorrelated relaxed molecular clock using a lognormal distribution and a Birth-Death model process of speciation as Tree Prior. For the complete mitochondrial genomic alignment (alignment I) the GTR $+\mathrm{G}+\mathrm{I}$ evolutionary model was used. For the partitioned gene analysis (alignment II) and partitioned predicted amino acids (alignment III) each partition was set with a specific evolutionary model as previously described (Supplementary table 5). Besides the partitioned gene analysis we also performed a more robust analysis based on the nucleotide saturation of each gene taking into account the partition of codons positions where the 1st and 2nd codon positions were split from the 3 rd codon position. The concatenated protein analysis was performed under the $\mathrm{mtREV}+\mathrm{G}+\mathrm{I}$ evolutionary model. The posterior probability tree for each alignment dataset were built combining the three independent runs of each analysis with LogCombiner program applying a burn-in of $25 \%$ and the consensus credible tree was obtained through the TreeAnnotator program. The timescale trees were plotted with Phyloch package version 1.5-3 (available on http://www.christophheibl.de/Rpackages.html) from R programming language. Tres topologies comparison were performed by plotting tanglegrams using the Dendextend R package ${ }^{54}$.

\section{Results}

\section{Sequencing and mitogenome characterization}

The sequenced mosquito samples generated a total of 84.2 million paired-end reads representing the seventeen species and eight genera (Aedeomyia, Aedes, Coquillettidia, Culex, Mansonia, Psorophora, Trichoprosopon and Uranotaenia). The amount of generated reads ranged from 1.1 million reads for Uranotaenia pulcherrima to 11.3 million reads for Aedes taeniorhynchus (Table 1). Searching on the SRA database we include other twenty mosquito species raw read datasets for mitogenome characterization representing six genera (Aedes, Anopheles, Culex, Psorophora, Tripteroides and Toxorhynchites). We characterized 35 new draft mitogenomes for Culicidae family in total. Sixteen out of seventeen mitogenomes were sequenced for the first time considering only the field-sampled species (Ad. squamipennis, Ae. scapularis, Ae. taeniorhynchus, Cq. albicosta, Cq. chrysonotum, Cq. hermanoi, Cq. juxtamansonia, Cq. venezuelensis, Cx. amazonensis, Cx. corniger, Ma. wilsoni, Ma.humeralis, Ma.titillans, Ps. cingulata, Tr. digitatum, Ur. pulcherrima). In summary, the newly characterized mitogenomes represent eight Culicidae genera (Aedeomyia, Coquillettidia, Mansonia, Psorophora, Trichoprosopon, Tripteroides, Toxorhynchites, and Uranotaenia) that had no mitochondrial genome data available at the moment.

The coverage breadth of the sequenced draft mitogenomes ranged from $3.699 \mathrm{bp}$ to $15.660 \mathrm{bp}$ for Ma. humeralis and Ps. cingulata respectively (Table 1, Figure 1) with and average 
of $72.80 \%$ and a coverage depth average of 20.01 fold (Table 1). Annotation of the protein coding genes (PCG) identified in the field-collected mosquitoes ranged from 7 to 13 . All seventeen mitogenomes showed the two rRNA genes except Ae. scapularis genome. While tRNAs annotation ranged from 5 to 21 genes, except for Ae. taeniorhynchus and Cx. nigripalpus that showed all tRNAs genes (Table 2). Although some PCGs were not assembled we could annotate the barcode Cytochrome oxidase I gene in all seventeen mitogenomes (Supplementary table 6). The mitogenomes characterized from SRA data showed a coverage breadth ranging from 5.992 to $15.960 \mathrm{bp}$ for Ae. riversi and An. freeborni respectively (Figure 2). In general those assemblies showed an average coverage breadth of $88.42 \%$ and from 9 to 34 out of 37 mitochondrial genes were annotated with MITOS (Table 1). Although some of the SRA data came from RNA-Seq we were able to identify almost all PCGs of these mosquito species. PCGs annotation ranged from 7 for $T p$. aranoides to 13 for some species (Supplementary table 6, Figure 2).

\section{Evolutionary analysis}

In order to establish the phylogenetic relationship of Culicidae family we performed alignments with nucleotide and amino acid datasets taking into consideration or not gene/protein partitioning. Since several genes showed nucleotide saturation at the third codon position we also partitioned the codons of each PCG (Supplementary file 1). Topology of the phylogenetic trees built with those different alignments were mostly in agreement but also showed some clade grouping differences. Aedeomyia, Uranotaenia and Toxorhynchites genus were basal to the Culicinae subfamily but different grouping between them and uncertainty in the deep branching pattern appeared between analysis (Supplementary figure 2 and 3). Moreover, a number of intra genus incongruences between trees was also observed in the Culex, Anopheles and Aedes genera (Supplementary figure 2 and 3). The comparison between amino acid phylogenies against partitioned codon PCG phylogeny showed a similar topology supporting the basal position of some clades as Uranotaenia and Aedeomyia from Culicinae subfamily. Nevertheless, some branches within genera such as Coquillettidia, Culex, Aedes and Anopheles showed different positions (Supplementary figure 3).

The Culicidae family split from other dipterans during Permian period around 273 million years ago (MYA) (Figure 3, node A and Supplementary table 7). While the most recent common ancestor of the Culicidae family emerged in the Jurassic period around 182 MYA with the Anophelinae and Culicinae subfamilies origin (Figure 3, node B). In the subfamily Anophelinae, the Chagasia genus showed basal to Bironella and Anopheles genera with speciation in the Cretaceous period around 145 MYA (Figure 3, node C). The last two genera showed speciation times from 110 MYA until the last 2 MYA in the gambiae species complex (Figure 3, nodes D and E, respectively). 
The subfamily Culicinae formed a monophyletic group with the TMRCA (The most recent common ancestral) occurring around 160 MYA in Jurassic period (Figure 3, node F). The basal lineage from Culicinae subfamily was two species representing the Uranotaenia and Aedeomyia genera which shared a common ancestor around 151 MYA (Figure 4, node H). The split of Culicini and Aedini tribes from Toxorhynchitini, Sabethini, Mansoniini has occurred around 157 MYA (Figure 4, node I). The Toxorhynchites genus has shown to be basal in relation to Sabethini and Mansoniini tribes. Among Sabethini members, the Tripteroides genus was positioned as a basal lineage and Trichoprosopon genus speciated from other Sabethes species around 113 MYA (Figure 4, node J). The Mansoniini tribe has been placed as a sister clade to the Sabethini tribe. The Mansonia and Coquillettidia genera were both monophyletic with speciation processes starting around 88 and 85 MYA respectively (Figure 4, nodes K and L, respectively). The Ma. titillans species showed basal in relationship to Ma. wilsoni and Ma. humeralis that speciated in Neogene period (5,71 MYA, node M in Figure 4). Inside the Coquillettidia genus, Cq. chrysonotum showed a basal position in relationship the other species. The diversification inside Coquillettidia occurred between 85 to 30 MYA with origin of Cq. chrysonotum, Cq. albicosta, Cq. juxtamansonia and Cq. venezuelensis $+C q$. hermanoi respectively (Figure 4). The diversification between Culex and Aedini taxa occurred in the Cretaceous period around 130 MYA (Figure 4, node N). While the split of Aedes and Psorophora genera occurred around 102 MYA and the speciation of Ps. albipes and Ps. cingulata occurred in Paleogene around 63 MYA (Figure 4, node $\mathrm{O}$ and $\mathrm{P}$, respectively). Among the Aedes species, Ae. fluviatilis is the basal and early diverged species (94 MYA, node Q in Figure 4) from the genus. Ae. polynesiensis and Ae. riversi were closely to Ae, albopictus (Figure 4, node R). Another clade formed closely to $A e$. aegypti clade was composed by species from Ochlerotatus (Ae. vigilax, Ae. taeniorhynchus, Ae. scapularis, Ae. detritus and Ae. camptorhynchus), Finlaya subgenera (Ae. notoscriptus and Ae. alboannulatus) and Haemagogus genus, where Ae. vigilax was the basal species (Figure 4, node S). The Finlaya subgenus has a paraphyletic status when the positioning of Ae. alboannulatus and Ae. notoscriptus is observed (Figure 4). The neotropical species Ae. taeniorhynchus and Ae. scapularis formed a clade and diverged between themself around 56 MYA (Figure 4, node T). Among Culex species, Cx. amazonensis showed to be the basal and the earlier diverged species from the genus with the split from the other species occurring around 103 MYA (Figure 4, node $\mathrm{U})$. The pipiens group showed an origin around 22 MYA where the Australian species $C x$. australicus and $C x$. globocoxitus have been placed in basal position in relationship to other $C x$. pipiens species (Figure 4, node V). The $C x$. torrentium was placed inside pipiens group. The $C x$. corniger was placed as basal species from coronator group of Culex with speciation around 11 MYA as well as $C x$. nigripalpus that speciated from $C x$. chidesteri, $C x$. mollis, $C x$. declarator and $C x$. bidens around 13 MYA (Figure 4, node $\mathrm{X}$ and $\mathrm{Y}$ respectively). While $C x$. tarsalis formed a clade with $C x$. brami with a speciation time of 20 MYA (Figure 4, node Z). 


\section{Lineage through time (LTT) section}

The LTT analysis showed the radiation processes within Culicidae family were constant through the last million years with some peaks (Figure 5A). After the first lineage emergences splitting the subfamilies Anophelinae and Culicinae occurred a rise in speciation processes up to 100 MYA in Cretaceous period. Another speciation peak occurred close to 75 MYA. After the peak close to 75 MYA the speciation processes occured in a more constant pace until before 25 MYA and showed a rise in speciation only in the last million years. Within Anophelinae subfamily a constant pattern of speciation occurred with few peaks (Figure 5B). Likewise, the LTT analysis within Culicinae subfamily showed a similar pattern seen in Anophelinae LTT (Figure 5C).

\section{Discussion}

Mitogenomes have been widely used to elucidate the evolutionary history of several species of animals and plants and can also be used as barcode sequences for species identification 14,55,56. The first mosquito mitogenome from Anopheles gambiae was sequenced using the Sanger method on PCR amplified fragments ${ }^{25}$ and further mitochondrial genomes were slowly sequenced along with whole genome projects. Currently, most studies have been using high throughput sequencing or PCR amplification followed by high throughput sequencing to characterize several mitogenomes at once ${ }^{20,21,24}$ in a wide range of insect species showing promising results to reconstruct mitogenomes ${ }^{30,57}$ Here, we performed low-coverage sequencing to assemble and characterize the mitogenomes from many mosquito species generating around 4.95 million reads per species. We were able to assemble sixteen draft mitogenomes from Culicidae species, not characterized so far, belonging to 8 different genera. Richter et al. $(2015)^{30}$ and collaborators suggested that a minimum of 10 million reads are needed to recovery mitogenomes with higher coverage breadth and datasets having around 1 million reads usually generate highly incomplete mitogenomes, but we were able to assemble nearly complete mitogenomes with as low as 1.1 million reads. Besides, the draft genomes assembled contained enough phylogenetic markers necessary for robust phylogenetic analysis.

In addition, we also reconstructed mitochondrial genomes from available RNA-Seq data. We were able to reconstruct twenty additional nearly complete draft mitogenomes for Culicidae species not studied so far at the mitochondrial genomic level. No study has been able to reconstruct complete mitochondrial genomes from RNA-Seq data, mainly due the endonuclease activity on transcripts or loss of mitochondrial transcripts due to the enrichment steps normally used during the sequencing library construction ${ }^{28}$. However, the remaining mitochondrial data available in different RNA-Seq datasets still can be used to mine mitogenome sequences for understudied species ${ }^{58-60}$. The datasets used for mitogenomes characterization showed around 
0.073 to $8.034 \%$ of mitochondrial reads. In total, we obtained 37 draft mitogenomes representing 11 genera (Anopheles, Uranotaenia, Aedeomyia, Toxorhynchites, Tripteroides, Trichoprosopon, Mansonia, Coquillettidia, Psorophora, Aedes and Culex).

Several efforts have been made to better understand the taxonomic status inside of the Culicidae family, but most studies that included a substantial number of species employed only morphological data ${ }^{61}$ and the ones using molecular information are mainly based on a low number of species or used limited molecular markers ${ }^{62-65}$. Hence, there are still many non-studied species and unresolved phylogenetic relationships in genera such as Aedes, Armigeres, Coquillettidia, Culex, Mansonia, Mimomyia, Psorophora, Topomyia, Tripteroides, Toxorhynchites, Uranotaenia and Wyeomyia ${ }^{61}$. The Anophelinae subfamily phylogenetic relationship was recently investigated using the mitochondrial genomes from many species and the authors proposed a number of taxonomic status changes such as the elevation of some groups from the subgenus to genus level ${ }^{19}$. Some other studies also characterized the mitogenomes of some species to solve the phylogenetic positioning of culicids, however, most of them focused on a specific group (Anopheles, Culex and Sabethes) or few genera of the Culicidae family $10,11,19-21,66$.

The phylogenetic analysis including the thirty-five mitogenomes assembled in this study comprising eight Culicidae genera is highly congruent regarding the monophyly of large species groups. Both Culicinae and Anophelinae subfamily and Anopheles, Sabethes, Mansonia, Coquillettidia, Psorophora and Culex genera were monophyletic. Moreover, we also observed similar dating, estimates as reported in the literature, for some key ancestors. For instance, the split between Culicidae and other dipterans occurred around 273 MYA (HPD95\%:243.79-332.41) while other studies suggested that this split could have occurred around 259 and 260 MYA using mitogenomes and phylogenomics analysis respectively ${ }^{11,65}$. The split between the two subfamilies: Anophelinae and Culicinae occurred in the Jurassic period around 182 MYA (HPD95\%:145.88-232.95). Similar estimates were obtained in other studies around 190-195 MYA ${ }^{67,68}$. Different evolutionary rate of molecular markers, incomplete species sampling and different algorithms used to reconstruct the species phylogeny could result in different time estimates (Hao et al. (2017)).

The evolutionary history of the Anophelinae subfamily has been more extensively studied considering the number of species analyzed and the different morphological and molecular markers used including whole phylogenomic analysis ${ }^{64}$ as well as mitogenomes (FOSTER et al. 2017). However, these studies have not assessed the diversification of some basal groups such as Chagasia and Bironella. In our analysis, those groups showed to be the early diverged lineages from Anophelinae subfamily, emerging in the Upper and Lower Cretaceous, respectively (Figure 3). The Bironella genus showed as an ancestral lineage in relationship to the Anopheles genus including all subgenera assessed in our analysis such as Kerteszia, Nyssorhynchus, Anopheles and Cellia. This contrasts with other findings that positioned this genus inside the Anopheles genus using mitochondrial protein sequences from mitogenomes ${ }^{19}$. Previous studies, using both 
nuclear ribosomal sequences and fragments of mitochondrial genes COI and COII of Bi. gracilis ${ }^{69}$ and $\mathrm{Bi}$. hollandi ${ }^{70}$, have already suggested that positioning of Bironella inside Anopheles genus. These contrasting results show that the Bironella genus position and phyletic status is still open and a wide sampling of the genus is needed to solve it. Regarding the Anopheles species our analysis using mitogenomes showed a similar positioning as seen in other studies ${ }^{70,71}$.

The radiation inside the Culicinae subfamily is older than Anophelinae around 160 MYA (HPD95\%:128.09-204.91) in the Jurassic period (Supplementary figure 4 and 5). Inside Culicinae subfamily the clade composed by Uranotaenia and Aedeomyia genera are the earliest diverging branch with the split from the other genera occurring around 151 MYA (HPD95\%:117.92-195.06) (Figure 4). The Toxorhynchites amboinensis species analyzed was placed as a sister group of Sabethini and Mansoniini tribes showing a very ancient split from these genera around 149 MY (HPD95\%:118.74-191.45) corroborating findings from studies based on morphological characters which suggested that Aedeomyia, Uranotaenia and Toxorhynchites genera are ancient and basal groups inside of the Culicinae subfamily ${ }^{62,72} .{ }^{73,74}$. However, two studies based on six nuclear genes and 18S rDNA have shown the positioning of Uranotaenia sapphirina more closely related to Culicini and Aedini tribes respectively ${ }^{63,75}$ which warrants more in depth analysis in order to establish the true genus positioning and phyletic status.

Regarding the Sabethini tribe, our results are in line with previous works showing the monophyly of tribe, the basal positioning of Tripteroides (Tp. aranoides) and the sister positioning of Trichoprosopon genus ( $T r$. digitatum) ${ }^{20,24,63}$ (Figure 4). Our analysis demonstrated the origin of Sabethini tribe around 124 MYA (HPD95\%:97.93-160.21) in the Lower cretaceous period. Although limited data exists about the arboviral vectorial capacity of different mosquito species of this tribe, our phylogenetic data for the Sabethini group associated with the competence of different New World Sabethes species to transmit Yellow fever virus (YFV) ${ }^{76-78}$ and the demonstrated absence of competence of Old World Tripteroides species ${ }^{79}$ suggests that arboviral transmission competence emerged in the New World in the ancestral of the Sabethes genus between Upper Cretaceous and Paleogene (76.25 MYA - HPD95\%:58.26-99.06) after the split from the Tripteroides genus.

Up to now, few studies have investigated the phylogenetic positioning and speciation time of the neotropical Mansoniini tribe. In our analysis, the eight species from the Mansoniini tribe formed a monophyletic group and are a sister group of the Sabethini tribe. Our results are in contrast with Reidenbach et al. (2009) analysis that positioned a single Coquillettidia species (Cq. pertubans) as a sister group of Aedini. Our dataset covers a larger number of species from the Mansoniini tribe and Reidenbach et al. (2009) did not include any Mansonia species which probably biased their analysis. Both Coquillettidia and Mansonia genera are monophyletic groups (Figure 4). Although vector capacity information for most of the Mansoniini species investigated here are unknown, some studies were able to detect arboviruses such as Mayaro virus and Saint Louis encephalitis virus in Cq. venezuelensis and Ma. titillans respectively ${ }^{80-82}$. 
Furthermore, Ma. titillans species showed a vector competence to Venezuelan Equine Encephalomyelitis Virus being considered as a second vector of this arbovirus in the Peruvian Amazon ${ }^{83}$. Therefore, the basal positioning of these two species inside of the Mansonia and Coquillettidia genera suggest that others Mansoniini species may also be competent for transmitting arboviruses.

Within the Aedini tribe our results have shown the same basal positioning of Psorophora genus seen by Reidenbach et al. (2009). However, we estimated the split of Janthinosoma e Grabhamia subgenera through the first sequenced mitogenomes of Psorophora genus, Ps. cingulata and Ps. albipes, occurring around 63 MYA (HPD95\%:45.84-84.94) on Paleogene period. Regarding the Aedes genus, our results showed a paraphyletic group encompassing a single species from the Haemagogus genus which corroborates other findings with a larger number of Haemagogus species ${ }^{84}$. Besides, paraphyletic groups was also observed for Ochlerotatus (Ae. fluviatilis, Ae. taeniorhynchus, Ae. scapularis, Ae. vigilax, Ae. detritus e Ae. camptorhynchus) and Finlaya (Ae. notoscriptus e Ae. alboannulatus) subgenera while Stegomyia (Ae. aegypti, Ae. albopictus, Ae. riversi, Ae. polynesiensis) subgenera formed a monophyletic group (Figure 4). A previous study based on morphological cladistic analysis suggested the monophyly of Ochlerotatus and Finlaya subgenera ${ }^{85}$. Inside of the Aedes genus, Ae. fluviatilis is the earliest branch split around 94 MYA (HPD95\%:74.02-121.02), in contrast to other study that positioned it within other Aedes branches ${ }^{84}$. In summary, the Aedes genus is a paraphyletic group showing several phylogenetic incongruences even among studies that used different markers and species representatives. Hence further reclassification is needed following the current knowledge of phylogenetic relationships of these species.

Some studies demonstrated the vectorial competence of Ae. fluviatilis for Dengue Virus (DENV) in experimental conditions ${ }^{86,87}$. Besides, this species is also a potential vector for Dirofilaria immitis transmission ${ }^{88}$. The basal positioning of Ae. fluviatilis in relation to the other Aedes species suggests that the vectorial capacity for arboviruses and filarial transmission is an ancestral trait of the Aedes genus. This trait likely emerged between the Cretaceous and Paleogene periods (94.04-33.9 MYA - HPD95\%:74.02-121.02/24.82-45.09). It is corroborated by the abundant knowledge about more recent divergent species that inherited this trait such as Ae. aegypti and Ae. albopictus, that are known vectors of DENV, YFV and D. immitis ${ }^{3,4,89,90}$. Moreover, other species such as Ae. polynesiensis ${ }^{91,92}$, Ae taeniorhynchus $^{93}$, Ae. vigilax ${ }^{94}, \mathrm{Ae}$. scapularis ${ }^{93}$, Ae. notoscriptus ${ }^{94}$ are reported as potential or confirmed vectors of filarial worms.

Regarding the Culex genus, our analysis showed that $C x$. amazonensis and Cx, hortensis are one of the earliest diverged species from this genus dating around 103 MYA (HPD95\%:79.07-135.87) and 56 MYA (HPD95\%:43.69-73.86), respectively. Our results are in agreement with ${ }^{95}$ cladistic morphological analysis concerning the basal positioning of those species, however our mitogenomics data support $C x$. amazonensis as the earliest divergent species instead of $C x$. hortensis. Our analysis have placed $C x$. nigripalpus as sister group of clade composed by $C x$. chidesteri, $C x$. mollis, $C x$. declarator e $C x$. bidens with radiation around 
13 MYA (HPD95\%:9.82-17.37). While, Cx. corniger has placed as sister lineage from Coronator group. A previous study using a fragment of the COI gene have already suggest this positioning ${ }^{96}$ and our mitogenomics analysis supported this placement showing it speciation time around 11.85 MYA (HPD95\%:7.78-16.85) in the Neogene period. Much have been discussed about the members of Pipiens group, if $C x$. pipiens consist in a species or a group of sibling species ${ }^{95}$. Some authors describe the Pipiens group harboring the following species: $C x$. pipiens pipiens, $C x$. quinquefasciatus, Cx. pipiens pallens, Cx. pipiens molestus, Cx. australicus e $C x$. globocoxitus ${ }^{95,97}$. Other similar species such as $C x$. torrentium have not been considered as a member of Pipiens group due its genetic divergence to other species of the group ${ }^{98}$. A study based on analysis of ITS1 and ITS2 has already demonstrated the close relationship of $C x$. torrentium with Pipiens group ${ }^{99}$. Our analysis have positioned $C x$. torrentium within Pipiens group with australian members $C x$. globocoxitus and $C x$. australicus as basal clade suggesting that $C x$. torrentium may be a true species from the Pipens group. Our dating analysis estimated that the Pipiens group split from other Culex species around 40 MYA (HPD95\%:31.79-52.73) and the speciation process inside of Pipiens group occurred from 22 MYA (HPD95\%:16.73-28.91) up to 2.37 MYA (HPD95\%:1.53-3.37). Although the lower divergence time among some members of Pipiens group each "species" has specific ecological, physiological and behavioral characteristics ${ }^{98,100}$.

Our LTT analysis showed that the diversification within Culicidae family occured in a more or less continuous processes over time. However, at some points occurred a rise in speciation processes. Tang et al. (2018) described that at least three shifts in speciation rates in Culicidae family occurred around 180-195 MYA and the last around 30-24 MYA. This shift on speciation rates demonstrated that they are correlated with the split of subfamilies and the first lineages of mosquitoes. The latest shifts in recent speciation (30-24 MYA) correlate with some Anopheles and Culex speciation as seen in our results. However, it is important to note that the number of species and the representation of the species used in the phylogenetic analysis can drastically affect the LTT plot shape. Therefore, it is important to see those results with care to interpret speciation rate in mosquitoes.

\section{Conclusion}

Overall, we characterized the phylogenetic position and speciation time of the main groups of Culicidae family which emerged in the last 182 MYA between the Jurassic and Paleogene periods. Most of the different genera emerged in this range of time, but some recent speciation occurred as in the Culex genus. Interestingly, a burst in mammals speciation also occurred in the Neogene period likely driving the speciation of these species at that time ${ }^{67,101}$. Furthermore, the new phylogenetic knowledge generated allowed us to propose new hypotheses about some mosquito traits emergence and maintenance related with vector competence. More in 
depth studies trying to tease apart these different mechanisms considering the phylogeny of the Culicidae tree will benefit from the information generated in this work.

\section{Acknowledgements}

This research was supported by Fundação Oswaldo Cruz and Conselho Nacional de Desenvolvimento Científico e Tecnológico $(\mathrm{CNPq})$ under the project number PROEP/IAM (400742/2019-5). da Silva, A.F received a masters scholarship from Coordenação de Aperfeiçoamento de Pessoal de Nível Superior (CAPES). We thank Cláudio Júlio da Silva and Edivaldo José Apolinário from Núcleo de Vigilância à Saúde e do Meio Ambiente by the support in mosquito sampling from Moreno municipality. We thank the Núcleo de Bioinformática and Núcleo de Plataformas Tecnológicas (NPT) of IAM by the computational infrastructure and sequencing platform respectively.

\section{Author contributions statement}

Wallau, G.L conceived, designed the research, performed mosquito sampling and wrote the paper. da Silva, A.F performed the mosquito sampling, molecular experiments, bioinformatics analysis and drafted the paper. Machado, L.C performed the mosquito sampling, molecular experiments and contributed to drafted the manuscript. Paula, M.B and Pessoa, C.J.S performed the taxonomic identification and contributed to write the paper. Bronzoni, R.V.M and Santos, M.A.V.M performed mosquito sampling and contributed to write the paper. All authors read and approved the final version of the manuscript.

\section{Additional information}

Competing Interests: The authors declare that they have no competing interests. 
Table 1. General statistics for sequenced draft mitogenome.

\begin{tabular}{|c|c|c|c|c|c|c|c|c|c|c|}
\hline Species & $\begin{array}{c}\text { Total of } \\
\text { reads } \\
\text { (Mi) }\end{array}$ & $\begin{array}{c}\text { Final } \\
\text { assembly } \\
\text { (bp) }\end{array}$ & $\begin{array}{c}\text { Breadth } \\
\text { coverage* }\end{array}$ & $\begin{array}{l}\text { Mapped } \\
\text { reads }^{1}\end{array}$ & $\begin{array}{c}\text { Final } \\
\text { depth } \\
\text { coverage }\end{array}$ & $\begin{array}{c}\% \text { of mito } \\
\text { reads }\end{array}$ & $\begin{array}{c}\text { Total of } \\
\text { genes }\end{array}$ & PCG & rRNA & tRNA \\
\hline Ae. taeniorhynchus & 11.3 & 14.732 & $95.10 \%$ & 8.174 & 37.73 & 0.07234 & 37 & 13 & 2 & 22 \\
\hline Ma. wilsoni & 8.2 & 10.443 & $67.41 \%$ & 3.522 & 23.27 & 0.04295 & 28 & 12 & 2 & 14 \\
\hline Tr. digitatum & 7.6 & 8.282 & $53.46 \%$ & 729 & 5.99 & 0.00959 & 28 & 10 & 2 & 16 \\
\hline Ae. scapularis & 7 & 7.795 & $50.32 \%$ & 218 & 1.99 & 0.00311 & 25 & 11 & 1 & 13 \\
\hline Ma. titillans & 6.6 & 11.181 & $72.18 \%$ & 7.338 & 46.60 & 0.11118 & 27 & 11 & 2 & 14 \\
\hline Cq. chrysonotum & 6.2 & 12.032 & $77.67 \%$ & 1.955 & 11.37 & 0.03153 & 35 & 13 & 2 & 20 \\
\hline Cq. juxtamansonia & 5.5 & 7.711 & $49.78 \%$ & 826 & 7.18 & 0.01502 & 18 & 8 & 2 & 8 \\
\hline Ps. cingulata & 4.9 & 15.660 & $101.09 \%$ & 3.551 & 16.33 & 0.07247 & 36 & 13 & 2 & 21 \\
\hline Cx. nigripalpus & 4.8 & 14.492 & $93.55 \%$ & 3.633 & 17.30 & 0.07569 & 37 & 13 & 2 & 22 \\
\hline Cq. venezuelensis & 4.3 & 13.912 & $89.81 \%$ & 2.706 & 13.42 & 0.06293 & 34 & 13 & 2 & 19 \\
\hline Ad. squamipennis & 3.9 & 10.466 & $67.56 \%$ & 899 & 5.93 & 0.02305 & 27 & 9 & 2 & 16 \\
\hline Cx. corniger & 3.9 & 5.222 & $33.71 \%$ & 137 & 1.84 & 0.00351 & 20 & 9 & 2 & 9 \\
\hline Cx. amazonensis & 2.5 & 15.265 & $98.54 \%$ & 3274 & 15.87 & 0.13096 & 36 & 13 & 2 & 21 \\
\hline Cq. albicosta & 2.4 & 14.689 & $94.82 \%$ & 26.487 & 115.40 & 1.10363 & 36 & 13 & 2 & 21 \\
\hline Ma. humeralis & 2.2 & 3.699 & $23.88 \%$ & 193 & 3.91 & 0.00877 & 14 & 7 & 2 & 5 \\
\hline Cq. hermanoi & 1.8 & 12.289 & $79.33 \%$ & 1.958 & 11.79 & 0.10878 & 26 & 10 & 2 & 14 \\
\hline Ur. pulcherrima & 1.1 & 13.845 & $89.37 \%$ & 781 & 4.23 & 0.07100 & 32 & 12 & 2 & 18 \\
\hline Average & 4.95 & 11.277 & $72.8 \%$ & 66.381 & 20.01 & 0.11450 & - & - & - & - \\
\hline \multicolumn{11}{|c|}{ Species from SRA data } \\
\hline Ae. albonnulatus & 45.6 & 14.314 & $92.40 \%$ & 2.645 .908 & 22.749 .53 & 5.80243 & 26 & 11 & 2 & 13 \\
\hline Ae. camptorhynchus & 41 & 13.825 & $89.25 \%$ & 1.461 .943 & 11.897 .19 & 3.56571 & 30 & 12 & 2 & 16 \\
\hline Ae. detritus & 83.6 & 14.707 & $94.94 \%$ & 2.228 .562 & 19.597.21 & 2.66574 & 31 & 13 & 2 & 16 \\
\hline Ae. fluviatilis & 6.2 & 14.360 & $92.70 \%$ & 3.22 .138 & 3.858 .73 & 5.19577 & 17 & 12 & 1 & 4 \\
\hline Ae. polynesiensis & 31.8 & 15.144 & $97.76 \%$ & 39.618 & 133.74 & 0.12458 & 34 & 12 & 2 & 20 \\
\hline Ae. riversi & 17 & 5.992 & $38.68 \%$ & 12.505 & 23.83 & 0.07356 & 17 & 10 & 1 & 6 \\
\hline An. albimanus & 101.1 & 15.674 & $101.18 \%$ & 668.072 & 4.304 .92 & 0.66080 & 34 & 12 & 2 & 20 \\
\hline An. aquasalis & 0.344 & 11.201 & $72.31 \%$ & 12.674 & 571.41 & 3.68002 & 14 & 9 & 2 & 3 \\
\hline An. freeborni & 148.8 & 15.960 & $103.03 \%$ & 1.231 .449 & 9.200 .00 & 0.82759 & 33 & 12 & 2 & 19 \\
\hline An. nuneztovari & 76.9 & 12.741 & $82.25 \%$ & 42.462 & 446.26 & 0.05522 & 23 & 12 & 2 & 9 \\
\hline An. quadriannulatus & 66.2 & 15.533 & $100.27 \%$ & 206.252 & 1.341 .11 & 0.31156 & 34 & 12 & 2 & 20 \\
\hline Cx. australicus & 44.8 & 15.195 & $98.09 \%$ & 3.222 .91 & 26.720 .50 & 7.19395 & 32 & 13 & 2 & 17 \\
\hline Cx. globocoxitus & 44.2 & 15.123 & $97.62 \%$ & 2.970 .924 & 24.483 .16 & 6.72155 & 31 & 12 & 2 & 17 \\
\hline Cx. hortensis & 91.4 & 13.702 & $88.45 \%$ & 3.053 .258 & 12.444 .56 & 3.34054 & 25 & 11 & 2 & 12 \\
\hline Cx. molestus & 27.2 & 11.440 & $73.85 \%$ & 558.460 & 4.194 .91 & 2.05316 & 21 & 13 & 2 & 6 \\
\hline Cx. tarsalis & 37.8 & 15.831 & $102.19 \%$ & 3.037 .171 & 28.602 .31 & 8.03484 & 33 & 12 & 2 & 19 \\
\hline Cx. torrentium & 47.8 & 12.652 & $81.67 \%$ & 5584.60 & 4.194 .91 & 1.16833 & 26 & 13 & 2 & 11 \\
\hline
\end{tabular}


bioRxiv preprint doi: https://doi.org/10.1101/871145; this version posted December 10, 2019. The copyright holder for this preprint (which was not certified by peer review) is the author/funder, who has granted bioRxiv a license to display the preprint in perpetuity. It is made available under aCC-BY 4.0 International license.

\begin{tabular}{ccccccccccc} 
Ps.albipes & 135.6 & 15.791 & $101.94 \%$ & 1.087 .575 & 8.166 .76 & 0.80205 & 33 & 12 & 2 & 19 \\
Tp. aranoides & 37.6 & 8.990 & $58.03 \%$ & 2874.39 & 4.887 .87 & 0.76447 & 9 & 7 & 2 & 0 \\
Tx. amboinensis & 100 & 15.775 & $101.83 \%$ & 2.220 .264 & 14.215 .32 & 2.22026 & 34 & 13 & 2 & 19 \\
\hline Average & 59.24 & 13.698 & $88.2 \%$ & 1.293 .401 & 5.108 & 2.6311 & - & - & - & -
\end{tabular}

* Coverage depth was calculated in relation to the average of culicidae mitochondrial genomes length $\overline{(15.491} \mathrm{pb})$. Bp represents base pairs. ${ }^{1}$ Mapped Reads against final assembly through MIRAbait tool. PCG represents protein coding genes. 
bioRxiv preprint doi: https://doi.org/10.1101/871145; this version posted December 10,2019 . The copyright holder for this preprint (which was not certified by peer review) is the author/funder, who has granted bioRxiv a license to display the preprint in perpetuity. It is made available under aCC-BY 4.0 International license.

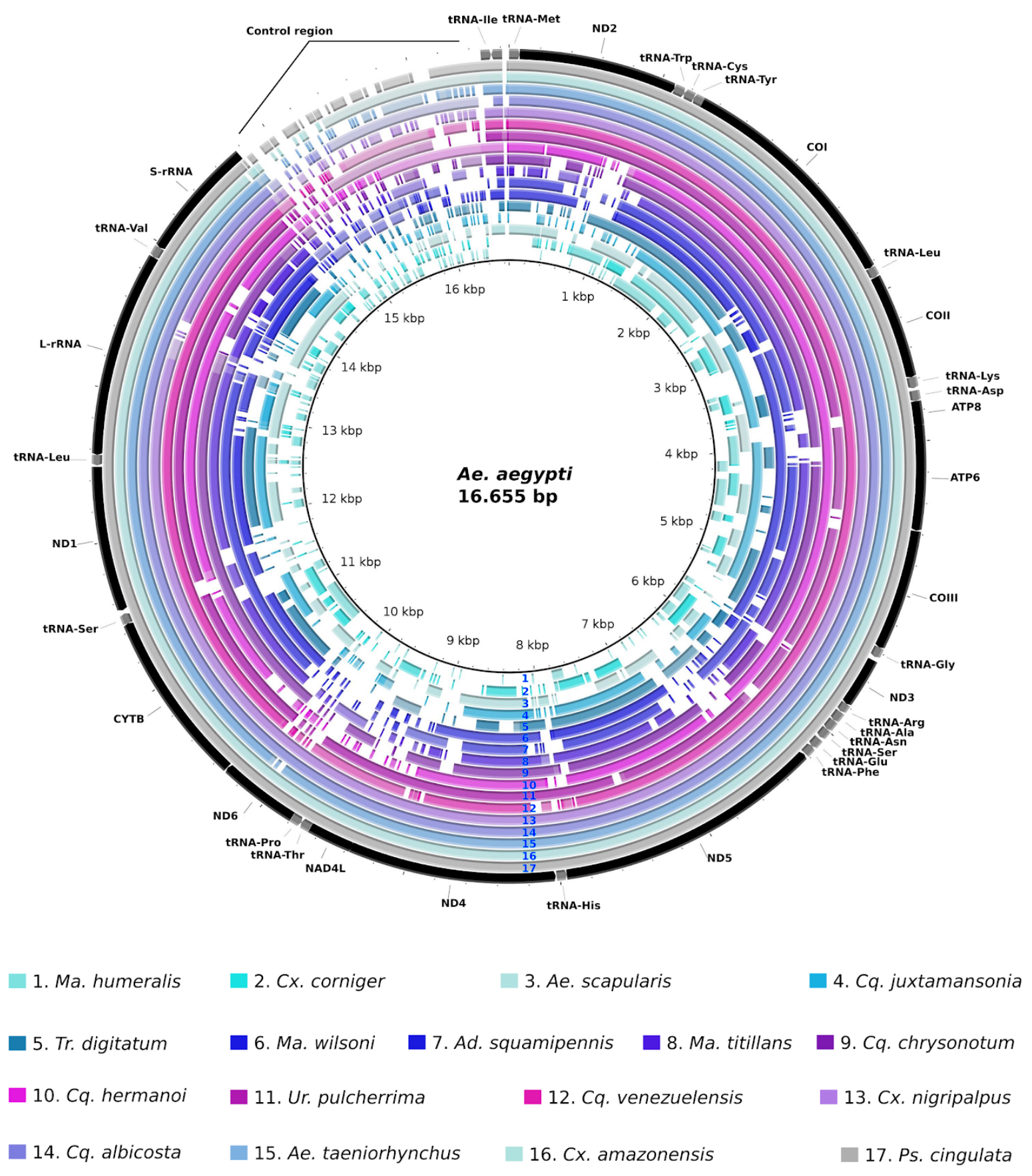

Figure 1. Comparative map of mitogenomes sequenced in relation to Ae. aegypti mitochondrial genome (NC_010241.1). 
bioRxiv preprint doi: https://doi.org/10.1101/871145; this version posted December 10,2019 . The copyright holder for this preprint (which was not certified by peer review) is the author/funder, who has granted bioRxiv a license to display the preprint in perpetuity. It is made available under aCC-BY 4.0 International license.

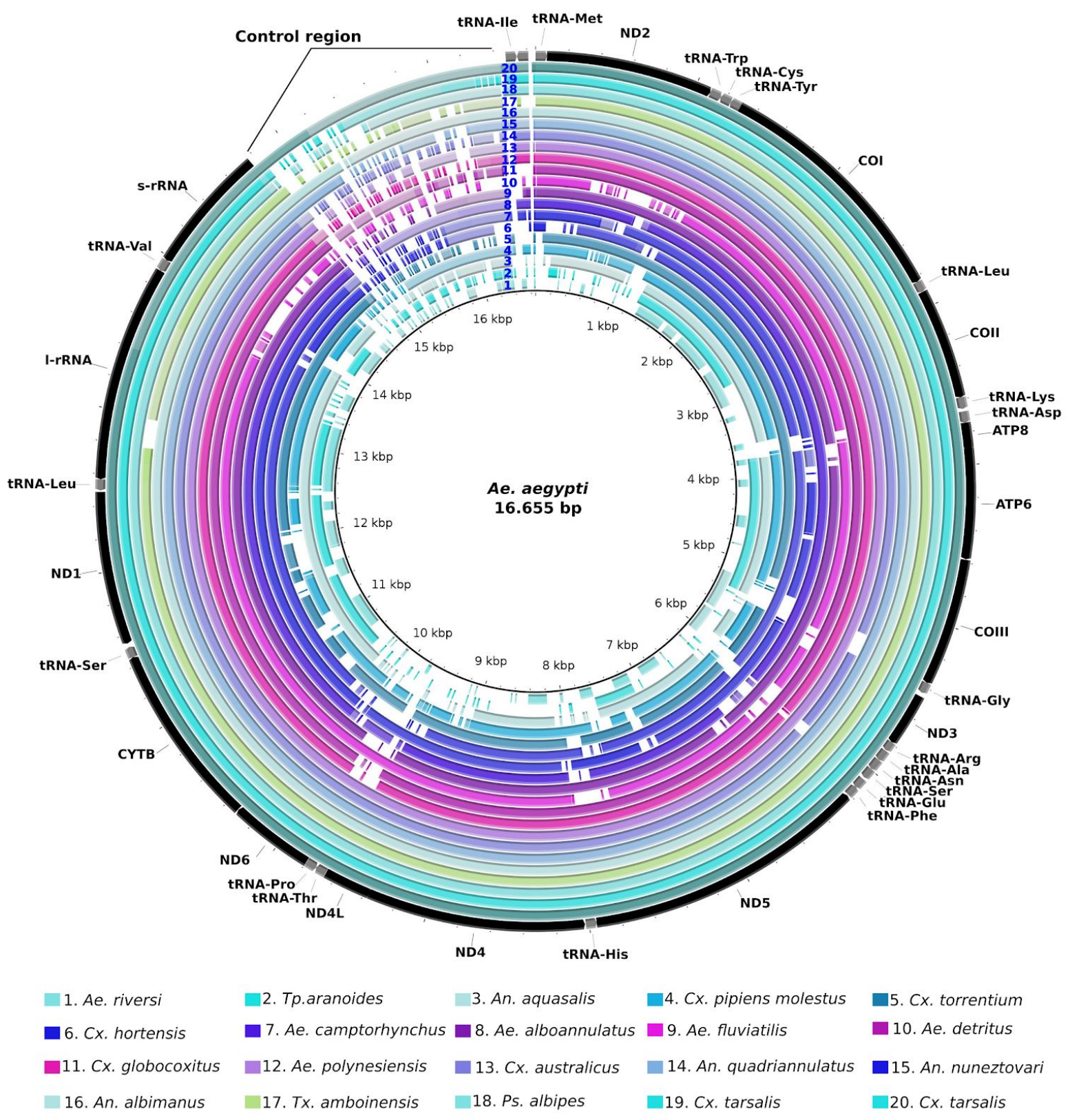

Figure 2. Comparative map of mitogenomes characterized from SRA data in relation to Ae. aegypti mitochondrial genome (NC_010241.1). 


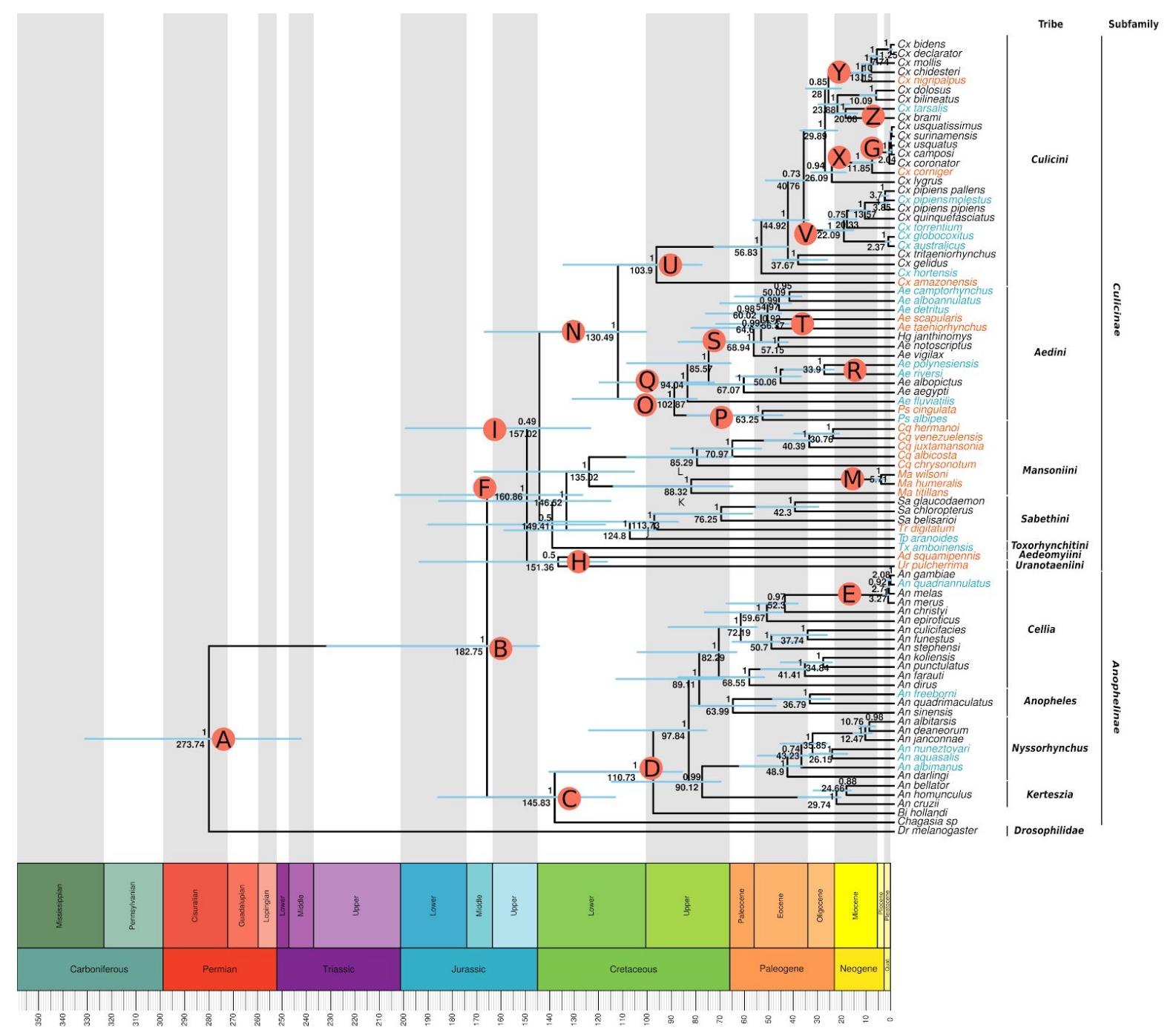

Figure 3. Evolutionary timescale of Culicidae family. Bayesian three reconstructed using nucleotide sequences of PCGs partitioned by gene and codon positions. Blue bars represent the HPD95\%. Numbers above and below the bars show the posterior probability and the predicted median dating for each node. Specific words inside the circles represent the nodes discussed in the text. 


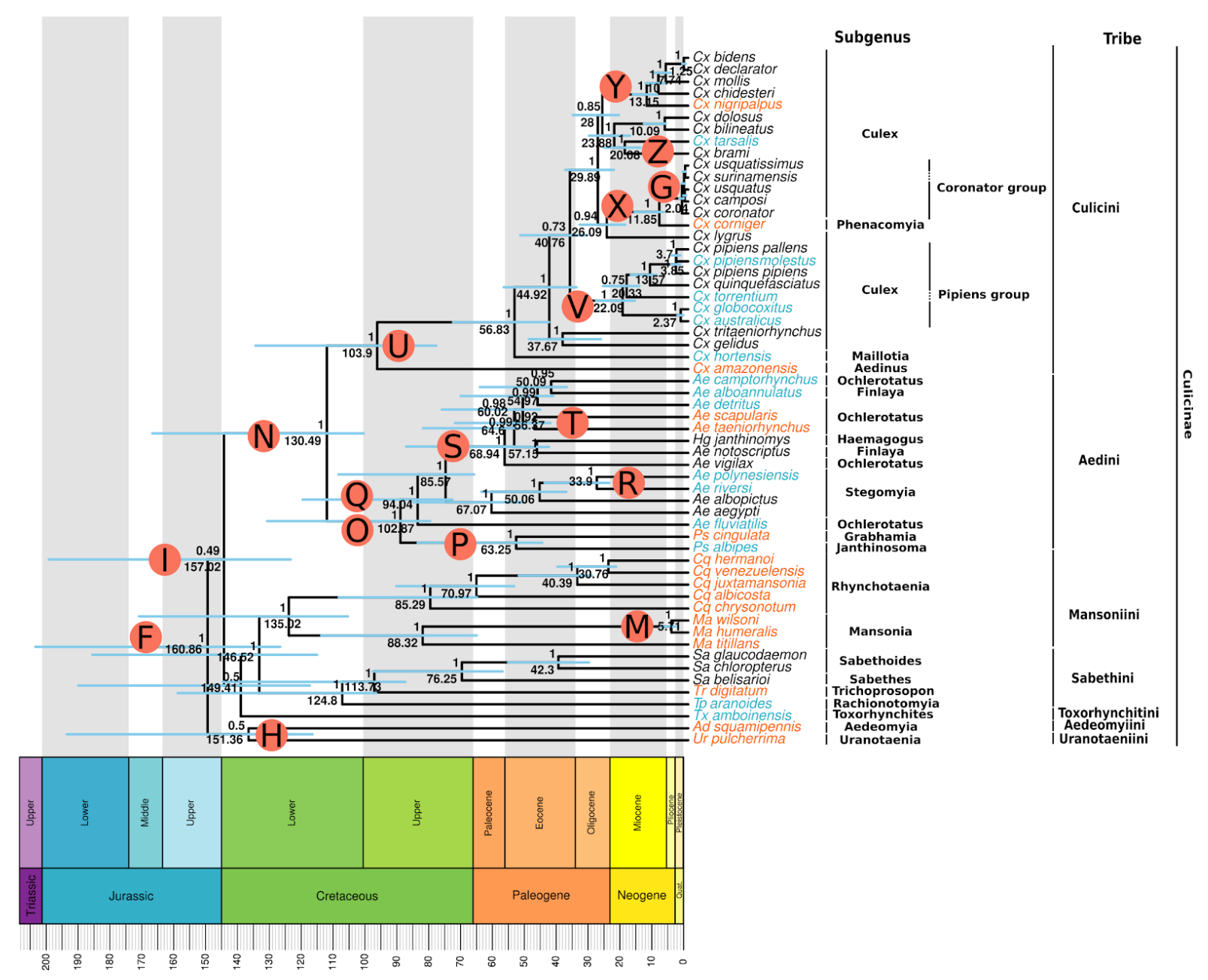

Figure 4. Evolutionary timescale of Culicinae subfamily. Tree was generated from BEAST analysis of partitioned PCG taking into account the split of codon positions. Blue bars in the nodes represent the HPD95\%. The numbers above and below the bars show the posterior probability and the predicted median dating respectively for each node. Specific words inside the circles represent the nodes discussed in the text. 


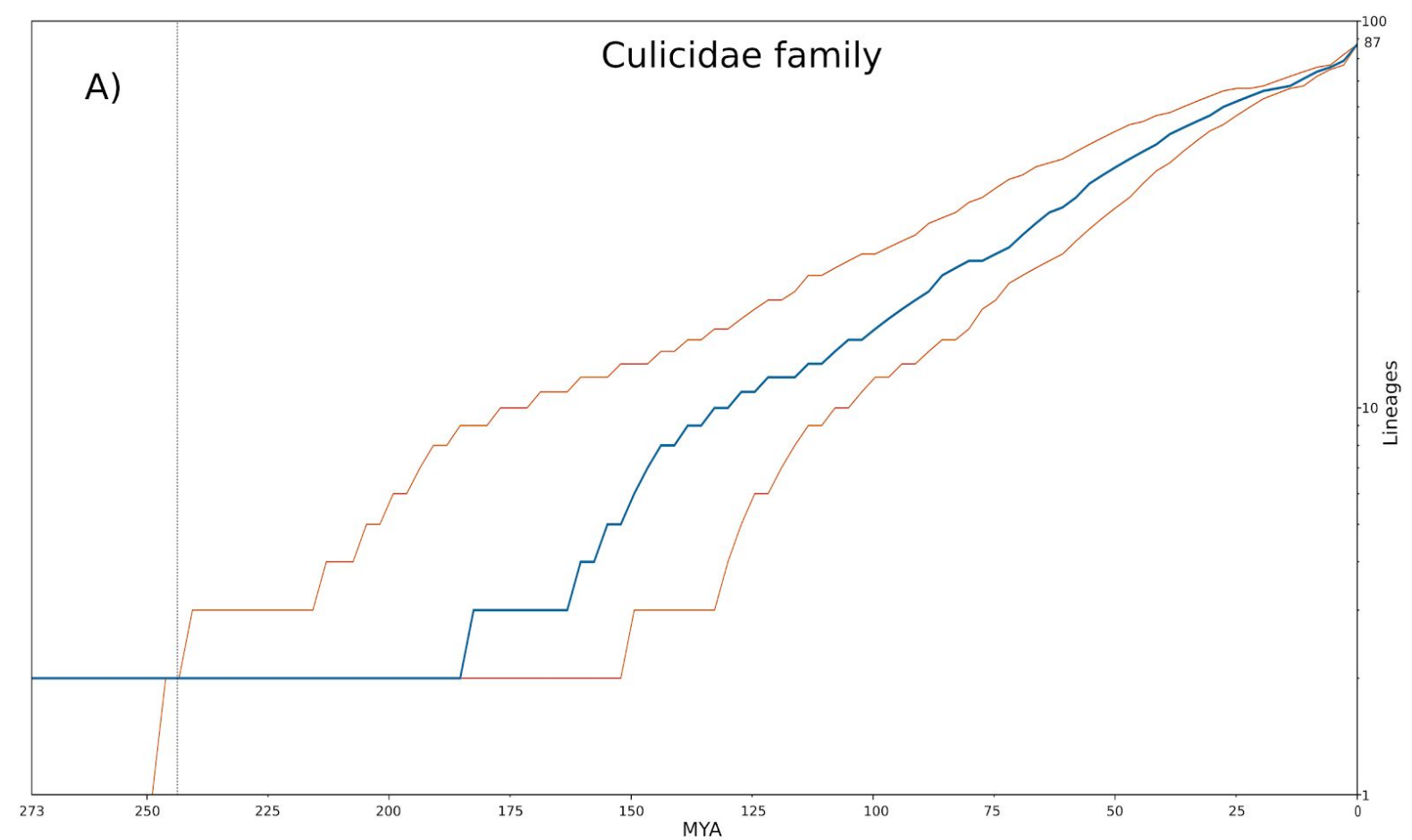

Anophelinae subfamily
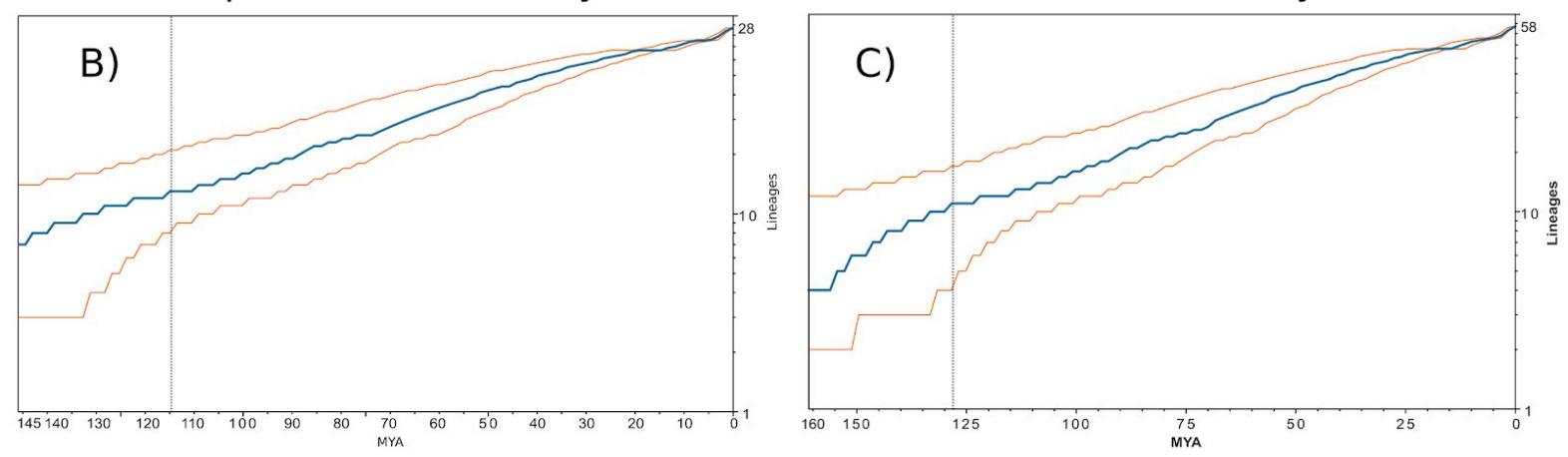

Figure 5. Lineages through time (LTT) plots representing the radiation within each taxa. A) LTT analysis showing the radiation within Culicidae family. B) LTT analysis showing the radiation within Anophelinae subfamily. C) LTT analysis showing the radiation within Culicinae subfamily. X-axis represents the time in million years ago (MYA). $\mathrm{Y}$-axis shows the number of lineages. Blue line represents the LTT trace and orange lines show the confidence intervals. 


\section{References:}

1. Molaei, G., Andreadis, T. G., Armstrong, P. M. \& Diuk-Wasser, M. Host-Feeding Patterns of Potential Mosquito Vectors in Connecticut, USA: Molecular Analysis of Bloodmeals from 23 Species of Aedes, Anopheles, Culex, Coquillettidia, Psorophora, and Uranotaenia. J. Med. Entomol. 45, (2008).

2. Lundström, J. O. et al. Transstadial transmission of Francisella tularensis holarctica in mosquitoes, Sweden. Emerg. Infect. Dis. 17, 794-799 (2011).

3. Tiawsirisup, S. \& Nithiuthai, S. Vector competence of Aedes aegypti (L.) and Culex quinquefasciatus (Say) for Dirofilaria immitis (Leidy). Southeast Asian J. Trop. Med. Public Health 37 Suppl 3, 110-114 (2004).

4. Wilson, M. E. \& Schlagenhauf, P. Aedes and the triple threat of DENV, CHIKV, ZIKV Arboviral risks and prevention at the 2016 Rio Olympic games. Travel Med. Infect. Dis. 14, $1-4(2015)$.

5. Shragai, T., Tesla, B., Murdock, C. \& Harrington, L. C. Zika and chikungunya: mosquito-borne viruses in a changing world. Ann. New York Acad. Sci. 1399, 61-77 (2016).

6. Norris, D. E. Mosquito-borne Diseases as a Consequence of Land Use Change. 19-24 (2003). doi:10.1007/s 10393-004-0008-7

7. Pereira Serra, O., Fernandes Cardoso, B., Maria Ribeiro, A. L., dos Santos, F. A. L. \& Dezengrini Slhessarenko, R. Mayaro virus and dengue virus 1 and 4 natural infection in culicids from Cuiabá, state of Mato Grosso, Brazil. Memorias do Inst. Oswaldo Cruz 111, 20-29 (2012).

8. Weaver, S. C. Host range, amplification and arboviral disease emergence. Arch. Virol. 
Suppl. 33-44 (2003). doi:10.1007/3-211-29981-5_4

9. Weaver, S. C. \& Barrett, A. D. . Transmission cycles, host range, evolution and emergence of arboviral disease. Nat. Rev. Microbiol. 2, 789-801 (2003).

10. Chu, H. et al. The phylogenetic relationships of known mosquito (Diptera: Culicidae) mitogenomes. Mitochondrial DNA Part 0, 1-5 (2011).

11. Hao, Y.-J. et al. Complete mitochondrial genomes of Anopheles stephensi and An. dirus and comparative evolutionary mitochondriomics of 50 mosquitoes. Sci. Reports 7, 7666 (2016).

12. Behura, S. K. Molecular marker systems in insects: Current trends and future avenues. Mol. Ecol. 15, 3087-3113 (2005).

13. Mandal, S. D., Chhakchhuak, L., Gurusubramanian, G. \& Kumar, N. S. Mitochondrial markers for identification and phylogenetic studies in insects - A Review. DNA Barcodes 2, $1-9(2013)$.

14. Hebert, P. D. N., Cywinska, A., Ball, S. L. \& deWaard, J. R. Biological identifications through DNA barcodes. Proceedings. Biol. Sci. / R. Soc. 270, 313-21 (2001).

15. Ratnasingham, S. \& Hebert, P. D. N. BOLD: The Barcode of Life Data System (www.barcodinglife.org). Mol. Ecol. Notes 7, 355-364 (2005).

16. Curole, J. P. \& Kocher, T. D. Mitogenomics: digging deeper with complete mitochondrial genomes. Trends Ecol. \& Evol. 14, 394-398 (1999).

17. Birky, C. W. Uniparental inheritance of mitochondrial and chloroplast genes: mechanisms and evolution. Proc. Natl. Acad. Sci. United States Am. 92, 11331-11338 (1995).

18. Xia, X. Rapid evolution of animal mitochondrial DNA. in Rapidly Evolving Genes and Genetic Systems 73-82 (Oxford University Press, 2012). 
doi:10.1093/acprof:oso/9780199642274.003.0008

19. Foster, P. . et al. Phylogeny of anophelinae using mitochondrial protein coding genes. $R$. Soc. Open Sci. 4, (2016).

20. Aragão, A. de O. et al. Description and phylogeny of the mitochondrial genome of Sabethes chloropterus, Sabethes glaucodaemon and Sabethes belisarioi (Diptera: Culicidae). Genomics 0-1 (2017). doi:10.1016/j.ygeno.2018.03.016

21. Sun, L. et al. The complete mt genomes of Lutzia halifaxia, Lt. fuscanus and Culex pallidothorax (Diptera: Culicidae) and comparative analysis of 16 Culex and Lutzia mt genome sequences. Parasites \& Vectors 12, 1-13 (2018).

22. Boore, J. L. Animal mitochondrial genomes. Nucleic Acids Res. 27, 1767-80 (1997).

23. Cameron, S. L. Insect mitochondrial genomics: implications for evolution and phylogeny. Annu. Rev Entomol 59, 95-117 (2013).

24. Lorenz, C. et al. First record of translocation in Culicidae ( Diptera ) mitogenomes: evidence from the tribe Sabethini. 1-8 (2018).

25. Beard, C. B., Hamm, D. M. \& Collins, F. H. The mitochondrial genome of the mosquito Anopheles gambiae: DNA sequence, genome organization, and comparisons with mitochondrial sequences of other insects. Insect Mol. Biol. 2, 103-124 (1991).

26. Mitchell, S. E., Cockburn, A. F. \& Seawright, J. A. The mitochondrial genome of Anopheles quadrimaculatus species A: complete nucleotide sequence and gene organization. Genome 36, 1058-1073 (1993).

27. Briscoe, A. G., Hopkins, K. P. \& Waeschenbach, A. High-Throughput Sequencing of Complete Mitochondrial Genomes. Methods Mol. Biol. 1452, 45-64 (2014). 
28. Cameron, S. L. How to sequence and annotate insect mitochondrial genomes for systematic and comparative genomics research. Syst. Entomol. 39, 400-411 (2013).

29. Tang, M. et al. Multiplex sequencing of pooled mitochondrial genomes - A crucial step toward biodiversity analysis using mito-metagenomics. Nucleic Acids Res. 42, 1-13 (2013).

30. Richter, S., Schwarz, F., Hering, L., Böggemann, M. \& Bleidorn, C. The utility of genome skimming for phylogenomic analyses as demonstrated for glycerid relationships (annelida, glyceridae). Genome Biol. Evol. 7, 3443-3462 (2014).

31. Deiner, K. Long-range PCR allows sequencing of mitochondrial genomes from environmental DNA. Unpublished 2017, 1-27 (2015).

32. Plese, B. et al. Trimitomics: An efficient pipeline for mitochondrial assembly from transcriptomic reads in non-model species. Mol. Ecol. Resour. (2019). doi:10.1111/1755-0998.13033

33. Dierckxsens, N., Mardulyn, P. \& Smits, G. NOVOPlasty: De novo assembly of organelle genomes from whole genome data. Nucleic Acids Res. 45, (2015).

34. Hahn, C., Bachmann, L. \& Chevreux, B. Reconstructing mitochondrial genomes directly from genomic next-generation sequencing reads - A baiting and iterative mapping approach. Nucleic Acids Res. 41, (2012).

35. Bernt, M. et al. MITOS: Improved de novo metazoan mitochondrial genome annotation. Mol. Phylogenetics Evol. 69, 313-319 (2012).

36. Al-Nakeeb, K., Petersen, T. N. \& Sicheritz-Pontén, T. Norgal: Extraction and de novo assembly of mitochondrial DNA from whole-genome sequencing data. BMC Bioinforma. 18, 1-7 (2016). 
37. Lemos, P. da S. et al. Characterization of mitochondrial genome of Haemagogus janthinomys (Diptera: Culicidae). Mitochondrial DNA Part 28, (2017).

38. Neotropical Culicidae. 2, (1953).

39. Culicidologia médica: identificaçäo, biologia e epidemiologia. 2, (Edusp, 2002).

40. Ayres, C. F. J., Melo-Santos, M. A. V., Solé-Cava, A. M. \& Furtado, A. F. Genetic differentiation of Aedes aegypti (Diptera: Culicidae), the major dengue vector in Brazil. $J$. Med. Entomol. 40, 430-435 (2003).

41. Ewels, P., Magnusson, M., Lundin, S. \& Käller, M. MultiQC: summarize analysis results for multiple tools and samples in a single report. Bioinformatics 32, (2016).

42. Bolger, A. M., Lohse, M. \& Usadel, B. Trimmomatic: a flexible trimmer for Illumina sequence data. Bioinforma. 30, 2114-2120 (2014).

43. Chevreux, B., Wetter, T. \& Suhai, S. Genome sequence assembly using trace signals and additional sequence information. Ger. Conf. Bioinforma. (1998).

44. Alikhan, N. F., Petty, N. K., Ben Zakour, N. L. \& Beatson, S. a. BLAST Ring Image Generator (BRIG): simple prokaryote genome comparisons. BMC Genomic- 12, 402 (2010).

45. Katoh, K. \& Standley, D. M. MAFFT multiple sequence alignment software version 7: Improvements in performance and usability. Mol. Biol. Evol. 30, 772-780 (2012).

46. Retrieving publications from Library.

47. Larsson, A. AliView: A fast and lightweight alignment viewer and editor for large datasets. Bioinformatics 30, 3276-3278 (2010).

48. Xia, X. \& Xie, Z. DAMBE: software package for data analysis in molecular biology and evolution. J. Hered. 92, 371-373 (2001). 
49. Xia, X., Xie, Z., Salemi, M., Chen, L. \& Wang, Y. An index of substitution saturation and its application. Mol. phylogenetics Evol. 26, 1-7 (2003).

50. Lefort, V., Longueville, J.-E. \& Gascuel, O. SMS: Smart Model Selection in PhyML. Mol. Biol. Evol. 34, 2422-2424 (2017).

51. Darriba, D., Taboada, G. L., Doallo, R. \& Posada, D. ProtTest 3: fast selection of best-fit models of protein evolution. Bioinformatics 27, (2011).

52. Drummond, A. J., Suchard, M. a, Xie, D. \& Rambaut, A. Bayesian phylogenetics with BEAUti and the BEAST 1.7. Mol. Biol. Evol. 29, 1969-1973 (2011).

53. Rambaut, A., Drummond, A. J., Xie, D., Baele, G. \& Suchard, M. A. Posterior summarization in Bayesian phylogenetics using Tracer 1.7. Syst. Biol. 67, 901-904 (2017).

54. Galili, T. dendextend: an R package for visualizing, adjusting and comparing trees of hierarchical clustering. Bioinformatics 31, (2015).

55. Krzemińska, U. et al. Population mitogenomics provides insights into evolutionary history, source of invasions and diversifying selection in the House Crow (Corvus splendens). Heredity 120, 296-309 (2018).

56. Witt, K. E. et al. DNA analysis of ancient dogs of the Americas: identifying possible founding haplotypes and reconstructing population histories. J. Hum. Evol. 79, 105-118 (2015).

57. Trevisan, B., Alcantara, D. M. ., Machado, D. J., Marques, F. P. . \& Lahr, D. J. . Genome skimming is a low-cost and robust strategy to assemble complete mitochondrial genomes from ethanol preserved specimens in biodiversity studies. PeerJ 7, e7543 (2018).

58. Raz, T. et al. Protocol dependence of sequencing-based gene expression measurements. 
PLoS ONE 6, (2010).

59. Tian, Y. \& Smith, D. R. Recovering complete mitochondrial genome sequences from RNA-Seq: A case study of Polytomella non-photosynthetic green algae. Mol. Phylogenetics Evol. 98, 57-62 (2015).

60. Nabholz, B., Jarvis, E. D. \& Ellegren, H. Obtaining mtDNA genomes from next-generation transcriptome sequencing: A case study on the basal Passerida (Aves: Passeriformes) phylogeny. Mol. Phylogenetics Evol. 57, 466-470 (2009).

61. Harbach, R. E. The Culicidae (Diptera): A review of taxonomy, classification and phylogeny. Zootaxa 591-638 (2006). doi:10.1017/CBO9781107415324.004

62. Harbach, R. E. \& Kitching, I. J. Phylogeny and classification of the Culicidae (Diptera). Syst. Entomol. 23, 327-370 (1997).

63. Reidenbach, K. R. et al. Phylogenetic analysis and temporal diversification of mosquitoes (Diptera: Culicidae) based on nuclear genes and morphology. BMC Evol. Biol. 9, 298 (2008).

64. Highly evolvable malaria vectors: The genomes of 16 Anopheles mosquitoes. 347, (2014).

65. Chen, X.-G. et al. Genome sequence of the Asian Tiger mosquito, Aedes albopictus, reveals insights into its biology, genetics, and evolution. Proc. Natl. Acad. Sci. 112, E5907-E5915 (2014).

66. Demari-Silva, B. et al. Mitochondrial genomes and comparative analyses of Culex camposi, Culex coronator, Culex usquatus and Culex usquatissimus (Diptera: Culicidae), members of the coronator group. BMC Genomic- 16, 831 (2014).

67. Tang, C., Davis, K. E., Delmer, C., Yang, D. \& Wills, M. A. Elevated atmospheric CO2 
promoted speciation in mosquitoes (Diptera, Culicidae). Commun. Biol. 1, 182 (2017).

68. Moreno, M. et al. Complete mtDNA genomes of Anopheles darlingi and an approach to anopheline divergence time. 1-13 (2009).

69. Sallum, M. A. M. et al. Phylogeny of Anophelinae (Diptera: Culicidae) based on nuclear ribosomal and mitochondrial DNA sequences: Molecular phylogeny of Anophelinae. Syst. Entomol. 27, (2002).

70. Freitas, L. A. et al. Diversification of the genus Anopheles and a neotropical clade from the Late Cretaceous. PLoS ONE 10, 1-12 (2014).

71. Fontaine, M. C. et al. Mosquito genomics. Extensive introgression in a malaria vector species complex revealed by phylogenomics. Sci. 347, 1258524 (2015).

72. Harbach, R. E. Comparative and functional morphology of the mandibles of some fourth stage mosquito larvae (Diptera: Culicidae). Zoomorphologie 87, (1975).

73. Krzywinski, J., Wilkerson, R. C. \& Besansky, N. J. Evolution of mitochondrial and ribosomal gene sequences in anophelinae (Diptera: Culicidae): implications for phylogeny reconstruction. Mol. phylogenetics Evol. 18, 479-487 (2001).

74. Díaz-Nieto, L. M. et al. Distribution of Mosquitoes in the South East of Argentina and First Report on the Analysis Based on $18 \mathrm{~S}$ rDNA and COI Sequences. PLoS ONE 8, 1-10 (2012).

75. Shepard, J. J., Andreadis, T. G. \& Vossbrinck, C. R. Molecular phylogeny and evolutionary relationships among mosquitoes (Diptera: Culicidae) from the northeastern United States based on small subunit ribosomal DNA (18S rDNA) sequences. J. Med. Entomol. 43, 443-54 (2004). 
76. de Rodaniche, E., Galindo, P. \& Trapido, H. Experimental transmission of yellow fever by Central American species of Haemagogus and Sabethes chloropterus. Am. J. Trop. Med. Hyg. 5, 1022-1031 (1956).

77. Galindo, P., de Rodaniche \& Johnson, C. M. St. Louis encephalitis in Panama. I. Isolation of the virus from forest mosquitoes and human blood. Am. J. Trop. Med. Hyg. 8, 557-560 (1959).

78. Vasconcelos, P. F. et al. An epidemic of sylvatic yellow fever in the southeast region of Maranhao State, Brazil, 1993-1994: epidemiologic and entomologic findings. Am. J. Trop. Med. Hyg. 57, 132-137 (1997).

79. Judd, D. D. Review of the systematics and phylogenetic relationships of the Sabethini (Diptera: Culicidae). Syst. Entomol. 21, 129-150 (1995).

80. Aitken, T. H., Downs, W. G., Anderson, C. R., Spence, L. \& Casals, J. Mayaro virus isolated from a Trinidadian mosquito, Mansonia venezuelensis. Sci. 131, 986 (1960).

81. Hoyos-López, R., Soto, S. U., Rúa-Uribe, G. \& Gallego-Gómez, J. C. Molecular identification of Saint Louis encephalitis virus genotype IV in Colombia. Memorias do Inst. Oswaldo Cruz 110, 719-725 (2015).

82. Beranek, M. D., Gallardo, R., Almirón, W. R. \& Contigiani, M. S. First detection of Mansonia titillans (Diptera: Culicidae) infected with St. Louis encephalitis virus (Flaviviridae: Flavivirus) and Bunyamwera serogroup (Peribunyaviridae: Orthobunyavirus) in Argentina. J. Vector Ecol. J. Soc. Vector Ecol. 43, 340-343 (2018).

83. Turell, M. J. et al. Vector competence of Peruvian mosquitoes (Diptera: Culicidae) for epizootic and enzootic strains of Venezuelan equine encephalomyelitis virus. J. Med. 
Entomol. 37, 835-839 (2000).

84. Soghigian, J., Andreadis, T. G. \& Livdahl, T. P. From ground pools to treeholes: convergent evolution of habitat and phenotype in Aedes mosquitoes. 1-13 (2016).

doi:10.1186/s12862-017-1092-y

85. Reinert, J. F., Harbach, R. E. \& Kitching, I. J. Phylogeny and classification of tribe Aedini (Diptera: Culicidae). Zool. J. Linn. Soc. 157, (2009).

86. Davis, N. C. \& Shannon, R. C. Studies on Yellow Fever in South America 1: Attempts to Transmit the Virus with Certain Aedine and Sabethine Mosquitoes and with Triatomas (Hemiptera). Am. J. Trop. Med. Hyg. s1-11, (1931).

87. Silva, J. B. L. et al. Wolbachia and dengue virus infection in the mosquito Aedes fluviatilis (Diptera: Culicidae). PloS one 12, e0181678 (2017).

88. Vezzani, D., Eiras, D. F. \& Wisnivesky, C. Dirofilariasis in Argentina: historical review and first report of Dirofilaria immitis in a natural mosquito population. Vet. Parasitol. 136, 259-273 (2006).

89. Miller, B. R., Mitchell, C. J. \& Ballinger, M. E. Replication, tissue tropisms and transmission of yellow fever virus in Aedes albopictus. Trans. R. Soc. Trop. Med. Hyg. 83, 252-255 (1989).

90. Cancrini, G. et al. Aedes albopictus is a natural vector of Dirofilaria immitis in Italy. Vet. Parasitol. 118, 195-202 (2003).

91. ROSIN, L. OBSERVATIONS ON THE EPIDEMIOLOGY OF HUMAN FILARIASIS IN FRENCH OCEANIA12. Am. J. Epidemiol. 61, (1955).

92. Nicolas, L. \& Scoles, G. A. Multiplex polymerase chain reaction for detection of Dirofilaria 
immitis (Filariidea: Onchocercidae) and Wuchereria bancrofti (Filarioidea:

Dipetalonematidae) in their common vector Aedes polynesiensis (Diptera: Culicidae). $J$.

Med. Entomol. 34, 741-744 (1997).

93. Lourenço-de-Oliveira, R. \& Deane, L. M. Presumed Dirofilaria immitis infections in wild-caught Aedes taeniorhynchus and Aeds scapularis in Rio de Janeiro, Brazil. Memórias do Inst. Oswaldo Cruz 90, (1995).

94. Bemrick, W. J. \& Moorhouse, D. E. Potential vectors of dirofilaria immitis in the Brisbane area of Queensland, Australia. J. Med. Entomol. 5, 269-272 (1968).

95. Harbach, R. E. Culex pipiens: species versus species complex taxonomic history and perspective. J. Am. Mosq. Control. Assoc. 28, 10-23 (2012).

96. Demari-Silva, B., Vesgueiro, F. T., Sallum, M. A. M. \& Marrelli, M. T. Taxonomic and phylogenetic relationships between species of the genus Culex (Diptera: culicidae) from Brazil inferred from the cytochrome c oxidase I mitochondrial gene. J. Med. Entomol. 48, 272-279 (2011).

97. Russell, R. C. A review of the status and significance of the species within the Culex pipiens group in Australia. J. Am. Mosq. Control. Assoc. 28, 24-27 (2012).

98. Farajollahi, A., Fonseca, D. M., Kramer, L. D. \& Marm Kilpatrick, A. "Bird biting” mosquitoes and human disease: a review of the role of Culex pipiens complex mosquitoes in epidemiology. Infect. Genet. Evol. J. Mol. Epidemiol. Evol. Genet. Infect. Dis. 11, 1577-1585 (2011).

99. Miller, B. R., Crabtree, M. B. \& Savage, H. M. Phylogeny of fourteen Culex mosquito species, including the Culex pipiens complex, inferred from the internal transcribed spacers 
of ribosomal DNA. Insect Mol. Biol. 5, 93-107 (1996).

100.Zittra, C. et al. Ecological characterization and molecular differentiation of Culex pipiens complex taxa and Culex torrentium in eastern Austria. Parasites \& vectors 9, 197 (2016).

101. Bininda-Emonds, O. R. P. et al. The delayed rise of present-day mammals. Nature 446, 507-12(2005). 
bioRxiv preprint doi: https://doi.org/10.1101/871145; this version posted December 10, 2019. The copyright holder for this preprint (which was not certified by peer review) is the author/funder, who has granted bioRxiv a license to display the preprint in perpetuity. It is made available

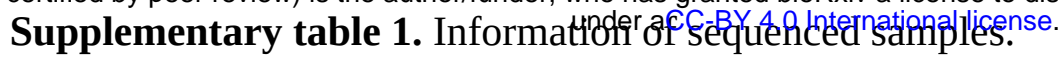

\begin{tabular}{|c|c|c|c|}
\hline Taxon & $\mathrm{N}^{\circ}$ of specimens & Location & Million of reads \\
\hline Ad. squamipennis & 3 & Aldeia-PE+REC ${ }^{2}$ & 3.9 \\
\hline Ae. scapularis & 7 & Juazeiro-BA & 7 \\
\hline Ae. taeniorhynchus & 10 & São Luís -MA & 11.3 \\
\hline Cq. hermanoi & 1 & Aldeia-PE & 1.8 \\
\hline Cq. chrysonotum & 14 & $\mathrm{PDI}^{1}$ & 6.2 \\
\hline Cq. albicosta & 3 & $\mathrm{PDI}^{1}$ & 2.4 \\
\hline Cq. juxtamansonia & 2 & $\mathrm{REC}^{2}$ & 5.5 \\
\hline Cq. venezuelensis & 4 & $\mathrm{PDI}^{1+\mathrm{REC}^{2}}$ & 4.3 \\
\hline Cx. amazonensis & 1 & $\mathrm{REC}^{2}$ & 2.5 \\
\hline$C x$. corniger & 5 & Mato Grosso & 3.9 \\
\hline Cx. nigripalpus & 6 & $\mathrm{PDI}^{1}$ & 4.8 \\
\hline Ma. titillans & 3 & $\mathrm{REC}^{2}$ & 6.6 \\
\hline Ma. wilsoni & 2 & $\mathrm{REC}^{2}$ & 8.2 \\
\hline Ma. humeralis & 1 & Aldeia-PE & 2.2 \\
\hline Ps. cingulata & 3 & Mato Grosso & 4.9 \\
\hline Tr. digitatum & 1 & Mato Grosso & 7.6 \\
\hline Ur. pulcherrima & 1 & $\mathrm{REC}^{2}$ & 1.1 \\
\hline
\end{tabular}

${ }^{1}$ Parque Estadual Dois Irmãos-PE . ${ }^{2}$ Reserva Ecológica de Carnijó-PE 
bioRxiv preprint doi: https://doi.org/10.1101/871145; this version posted December 10, 2019. The copyright holder for this preprint (which was not certified by peer review) is the author/funder, who has granted bioRxiv a license to display the preprint in perpetuity. It is made available

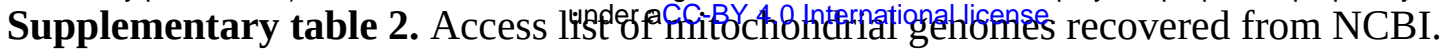

\begin{tabular}{|c|c|c|}
\hline Species & Access & Length (bp) \\
\hline Aedes aegypti & NC_010241.1 & 16.655 \\
\hline Aedes albopictus & NC_006817.1 & 16.665 \\
\hline Aedes notoscriptus & KM676218.1 & 15.846 \\
\hline Aedes vigilax & КР995260.1 & 15.877 \\
\hline Anopheles albitarsis & HQ335344.1 & 15.413 \\
\hline Anopheles bellator & KU551287.1 & 15.668 \\
\hline Anopheles christyi & NC_028214.1 & 14.967 \\
\hline Anopheles cruzii & KJ701506.1 & 15.449 \\
\hline Anopheles culicifacies & NC_027502.1 & 15.330 \\
\hline Anopheles darlingi & NC_014275.1 & 15.386 \\
\hline Anopheles deaneorum & HQ335347.1 & 15.424 \\
\hline Anopheles dirus & JX219731.1 & 15.404 \\
\hline Anopheles epiroticus & NC_028217.1 & 15.379 \\
\hline Anopheles farauti & NC_020770.1 & 15.412 \\
\hline Anopheles funestus & NC_008070.1 & 15.354 \\
\hline Anopheles gambiae & NC_002084.1 & 15.363 \\
\hline Anopheles homunculus & KU551283.1 & 15.739 \\
\hline Anopheles janconnae & HQ335348.1 & 15.425 \\
\hline Anopheles koliensis & JX219743.1 & 15.412 \\
\hline Anopheles melas & NC_028219.1 & 15.366 \\
\hline Anopheles merus & NC_028220.1 & 15.365 \\
\hline Anopheles punctulatus & NC_028222.1| & 15.322 \\
\hline Anopheles quadrimaculatus & NC_000875.1 & 15.455 \\
\hline Anopheles sinensis & NC_028016.1 & 15.076 \\
\hline Anopheles stephensi & NC_028223.1 & 15.387 \\
\hline Chagasia sp. & MF381717.1 & 15.717 \\
\hline Culex bidens & NC_037809.1 & 15.583 \\
\hline Culex gelidus & KX753344 & 15.600 \\
\hline Culex bilineatus & NC_037819.1 & 15.599 \\
\hline Culex brami & NC_037828.1 & 15.586 \\
\hline Culex coronator & NC_036006.1 & 15.576 \\
\hline Culex declarator & NC_037822.1 & 15.575 \\
\hline Culex dolosus & MF381620.1 & 15.851 \\
\hline Culex gelidus & KX753344.1 & 15.600 \\
\hline Culex lygrus & MF381718.1 & 15.572 \\
\hline
\end{tabular}


bioRxiv preprint doi: https://doi.org/10.1101/871145; this version posted December 10, 2019. The copyright holder for this preprint (which was not certified by peer review) is the author/funder, who has granted bioRxiv a license to display the preprint in perpetuity. It is made available

Culex mollis

Culex pipiens pallens

Culex pipiens pipiens

Culex quinquefasciatus

Culex surinamensis

Culex tritaeniorhynchus

Culex usquatissimus

Culex usquatus

Drosophila melanogaster

Haemagogus janthinomys

Sabethes belisarioi

Sabethes chloropterus

Sabethes glaucodaemon under aCC-BY 4.0 Internationald license.

15.576

KT851543.1

15617

NC_015079.1

14.855

NC_014574.1

15.587

MF381615.1

15.568

KT851544.1

14.844

NC_036007.1

15.574

NC_036005.1

15.573

U37541.1

19.517

NC_028025.1

15.698

MF957171.1

15.911

NC_037499.1

15.609

NC_037500.1

15.620

Supplementary table 3. Information about minered datasets from NCBI SRA database.

\begin{tabular}{|c|c|c|}
\hline Species & Access (SRA) & Original study \\
\hline Ae. alboannulatus & SRR5665565 & RNA-Seq (Species virome) \\
\hline Ae. camptorhynchus & SRR5665568 & RNA-Seq (Species virome) \\
\hline Ae. detritus & SRR6489869 & RNA-Seq (Differential gene expression) \\
\hline Ae. fluviatilis & SRR3574348 & RNA-Seq (Differential gene expression) \\
\hline Ae. polynesiensis & ERR1706659 & RNA-Seq (Comparative transcriptomes) \\
\hline Ae. riversi & ERR1706661 & RNA-Seq (Comparative transcriptomes) \\
\hline An. albimanus & SRR314655 & Genome sequencing \\
\hline An. aquasalis & SRR927456 & RNA-Seq (Transcriptome) \\
\hline An. freeborni & SRR908289 & RNA-Seq (Saliva transcriptome) \\
\hline An. nuneztovari & SRR6471062 & RNA-Seq (Saliva transcriptome) \\
\hline An. quadriannulatus & SRR529986 & Genome sequencing \\
\hline Cx. australicus & SRR5665566 & RNA-Seq (Species virome) \\
\hline Cx. globocoxitus & SRR5665567 & RNA-Seq (Species virome) \\
\hline Cx. hortensis & SRR1324883 & RNA-Seq (Comparative transcriptomes) \\
\hline Cx. molestus & SRR1462325 & RNA-Seq (Comparative transcriptomes) \\
\hline Cx. tarsalis & SRR5149179 & RNA-Seq (Transcriptome) \\
\hline Cx. torrentium & SRR1324895 & RNA-Seq (Comparative transcriptomes) \\
\hline Ps.albipes & SRR908278 & RNA-Seq (Saliva transcriptome) \\
\hline Tp. aranoides & SRR6155938 & RNA-Seq (Transcriptome) \\
\hline Tx. amboinensis & SRR2061845 & RNA-Seq (Transcriptome) \\
\hline
\end{tabular}


bioRxiv preprint doi: https://doi.org/10.1101/871145; this version posted December 10, 2019. The copyright holder for this preprint (which was not certified by peer review) is the author/funder, who has granted bioRxiv a license to display the preprint in perpetuity. It is made available

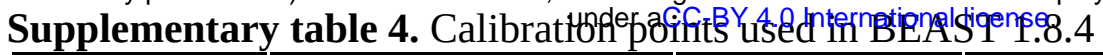

\begin{tabular}{|c|c|c|c|c|}
\hline Clade & Represented taxa & Minimum bound & Maximum bound & References \\
\hline Diptera & Culicidae and D. melanogaster & 240 & 241 & $\begin{array}{l}\text { KRZEMIŃSKI, } \\
\text { KRZEMIŃSKA \& } \\
\text { PAPIER, 1994 }\end{array}$ \\
\hline Culicidae & Culicinae e Anophelinae & 90 & 99 & $\begin{array}{c}\text { BORKENT \& } \\
\text { GRIMALDI, 2004² }\end{array}$ \\
\hline Culicinae & Culicinae & 76.5 & 79 & $\begin{array}{c}\text { POINAR, } \\
\text { ZAVORTINK., PIKE \& } \\
\text { JOHNSTON, } 2000^{3}\end{array}$ \\
\hline Anophelinae & Anophelinae & 15 & 34 & $\begin{array}{l}\text { ZAVORTINK \& } \\
\text { POINAR, } 2000^{4}\end{array}$ \\
\hline
\end{tabular}

Supplementary table 5. Evolutionary models used in BEAST analysis.

\begin{tabular}{|c|c|c|}
\hline Partition & Best nucleotide model ${ }^{1}$ & Best protein model $^{2}$ \\
\hline Nucleotide mitogenome alignment & $\mathrm{GTR}+\mathrm{G}+\mathrm{I}$ & - \\
\hline Concatenated protein alignment & - & $\mathrm{mtREV}+\mathrm{G}+\mathrm{I}$ \\
\hline Atp6 & $\mathrm{GTR}+\mathrm{G}+\mathrm{I}$ & $\mathrm{mtREV}+\mathrm{G}+\mathrm{I}$ \\
\hline Atp8 & $\mathrm{GTR}+\mathrm{G}$ & $\mathrm{JTT}+\mathrm{G}+\mathrm{I}$ \\
\hline COIII & $\mathrm{GTR}+\mathrm{G}+\mathrm{I}$ & $\mathrm{mtREV}+\mathrm{G}+\mathrm{I}$ \\
\hline COII & $\mathrm{GTR}+\mathrm{G}+\mathrm{I}$ & $m t R E V+G$ \\
\hline COI & $\mathrm{GTR}+\mathrm{G}+\mathrm{I}$ & $\mathrm{JTT}+\mathrm{G}+\mathrm{I}$ \\
\hline CytB & $\mathrm{GTR}+\mathrm{G}+\mathrm{I}$ & $\mathrm{mtREV}+\mathrm{G}+\mathrm{I}$ \\
\hline Nad1 & $\mathrm{GTR}+\mathrm{G}+\mathrm{I}$ & $\mathrm{JTT}+\mathrm{G}+\mathrm{I}$ \\
\hline Nad2 & $\mathrm{GTR}+\mathrm{G}+\mathrm{I}$ & $\mathrm{JTT}+\mathrm{G}$ \\
\hline Nad3 & $\mathrm{GTR}+\mathrm{G}+\mathrm{I}$ & $\mathrm{mtREV}+\mathrm{G}+\mathrm{I}$ \\
\hline Nad4L & $\mathrm{GTR}+\mathrm{G}+\mathrm{I}$ & $\mathrm{mtREV}+\mathrm{G}$ \\
\hline Nad4 & $\mathrm{GTR}+\mathrm{G}+\mathrm{I}$ & $\mathrm{JTT}+\mathrm{G}+\mathrm{I}$ \\
\hline Nad5 & $\mathrm{GTR}+\mathrm{G}+\mathrm{I}$ & $\mathrm{JTT}+\mathrm{G}$ \\
\hline Nad6 & $\mathrm{GTR}+\mathrm{G}+\mathrm{I}$ & $\mathrm{mtREV}+\mathrm{G}$ \\
\hline rrnL & $\mathrm{GTR}+\mathrm{G}+\mathrm{I}$ & - \\
\hline rrnS & $\mathrm{GTR}+\mathrm{G}+\mathrm{I}$ & - \\
\hline
\end{tabular}

${ }^{1}$ Best model as suggested by SMS. ${ }^{2}$ More likely model suggested by Prottest and present in BEAST 1.8.4. 
Supplementary table 6. Annotation of draft mitogenomes using MITOS.

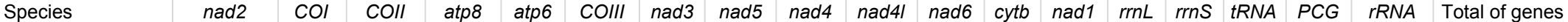

\begin{tabular}{|c|c|c|c|c|c|c|c|c|c|c|c|c|c|c|c|c|c|c|c|}
\hline Ad. squamipennis & 1 & 1 & 1 & - & - & 1 & 1 & 1 & 1 & - & - & 1 & 1 & 1 & 1 & 16 & 9 & 2 & 27 \\
\hline Ae. alboannulatus & 1 & 1 & 1 & - & - & 1 & 1 & 1 & 1 & 1 & 1 & 1 & 1 & 1 & 1 & 13 & 11 & 2 & 26 \\
\hline Ae. camptorhynchus & 1 & 1 & 1 & 1 & - & 1 & 1 & 1 & 1 & 1 & 1 & 1 & 1 & 1 & 1 & 16 & 12 & 2 & 30 \\
\hline Ae. detritus & 1 & 1 & 1 & 1 & 1 & 1 & 1 & 1 & 1 & 1 & 1 & 1 & 1 & 1 & 1 & 16 & 13 & 2 & 31 \\
\hline Ae. fluviatilis & 1 & 1 & 1 & 1 & 1 & 1 & - & 1 & 1 & 1 & 1 & 1 & 1 & 1 & - & 4 & 12 & 1 & 17 \\
\hline Ae. polynesiensis & 1 & 1 & 1 & 1 & - & 1 & 1 & 1 & 1 & 1 & 1 & 1 & 1 & 1 & 1 & 20 & 12 & 2 & 34 \\
\hline Ae. riversi & - & 1 & 1 & 1 & 1 & 1 & 1 & 1 & 1 & - & - & 1 & 1 & 1 & - & 6 & 10 & 1 & 17 \\
\hline Ae. scapularis & 1 & 1 & 1 & 1 & 1 & 1 & - & 1 & 1 & - & 1 & 1 & 1 & - & 1 & 13 & 11 & 1 & 25 \\
\hline Ae. taeniorhynchus & 1 & 1 & 1 & 1 & 1 & 1 & 1 & 1 & 1 & 1 & 1 & 1 & 1 & 1 & 1 & 22 & 13 & 2 & 37 \\
\hline An. albimanus & 1 & 1 & 1 & 1 & - & 1 & 1 & 1 & 1 & 1 & 1 & 1 & 1 & 1 & 1 & 20 & 12 & 2 & 34 \\
\hline An. aquasalis & 1 & 1 & 1 & 1 & - & 1 & - & 1 & 1 & - & - & 1 & 1 & 1 & 1 & 3 & 9 & 2 & 14 \\
\hline An. freeborni & 1 & 1 & 1 & 1 & - & 1 & 1 & 1 & 1 & 1 & 1 & 1 & 1 & 1 & 1 & 19 & 12 & 2 & 33 \\
\hline An. nuneztovari & 1 & 1 & 1 & 1 & - & 1 & 1 & 1 & 1 & 1 & 1 & 1 & 1 & 1 & 1 & 9 & 12 & 2 & 23 \\
\hline An. quadriannulatus & 1 & 1 & 1 & 1 & - & 1 & 1 & 1 & 1 & 1 & 1 & 1 & 1 & 1 & 1 & 20 & 12 & 2 & 34 \\
\hline Cq. albicosta & 1 & 1 & 1 & 1 & 1 & 1 & 1 & 1 & 1 & 1 & 1 & 1 & 1 & 1 & 1 & 21 & 13 & 2 & 36 \\
\hline Cq. chrysonotum & 1 & 1 & 1 & - & 1 & 1 & 1 & 1 & 1 & 1 & 1 & 1 & 1 & 1 & 1 & 20 & 12 & 2 & 34 \\
\hline Cq. hermanoi & 1 & 1 & 1 & 1 & 1 & 1 & 1 & 1 & 1 & - & - & 1 & - & 1 & 1 & 14 & 10 & 2 & 26 \\
\hline Cq. juxtamansonia & 1 & 1 & 1 & - & 1 & 1 & - & 1 & 1 & - & - & 1 & - & 1 & 1 & 8 & 8 & 2 & 18 \\
\hline Cq. venezuelensis & 1 & 1 & 1 & 1 & 1 & 1 & 1 & 1 & 1 & 1 & 1 & 1 & 1 & 1 & 1 & 19 & 13 & 2 & 34 \\
\hline Cx. amazonensis & 1 & 1 & 1 & 1 & 1 & 1 & 1 & 1 & 1 & 1 & 1 & 1 & 1 & 1 & 1 & 21 & 13 & 2 & 36 \\
\hline Cx. australicus & 1 & 1 & 1 & 1 & 1 & 1 & 1 & 1 & 1 & 1 & 1 & 1 & 1 & 1 & 1 & 17 & 13 & 2 & 32 \\
\hline Cx. corniger & 1 & 1 & 1 & 1 & - & 1 & - & 1 & 1 & 1 & - & 1 & - & 1 & 1 & 9 & 9 & 2 & 20 \\
\hline Cx. globocoxitus & 1 & 1 & 1 & 1 & - & 1 & 1 & 1 & 1 & 1 & 1 & 1 & 1 & 1 & 1 & 17 & 12 & 2 & 31 \\
\hline Cx. hortensis & 1 & 1 & 1 & - & - & 1 & 1 & 1 & 1 & 1 & 1 & 1 & 1 & 1 & 1 & 12 & 11 & 2 & 25 \\
\hline Cx. molestus & 1 & 1 & 1 & 1 & 1 & 1 & 1 & 1 & 1 & 1 & 1 & 1 & 1 & 1 & 1 & 6 & 13 & 2 & 21 \\
\hline Cx. nigripalpus & 1 & 1 & 1 & 1 & 1 & 1 & 1 & 1 & 1 & 1 & 1 & 1 & 1 & 1 & 1 & 22 & 13 & 2 & 37 \\
\hline Cx. tarsalis & 1 & 1 & 1 & 1 & - & 1 & 1 & 1 & 1 & 1 & 1 & 1 & 1 & 1 & 1 & 19 & 12 & 2 & 33 \\
\hline Cx. torrentium & 1 & 1 & 1 & 1 & 1 & 1 & 1 & 1 & 1 & 1 & 1 & 1 & 1 & 1 & 1 & 11 & 13 & 2 & 26 \\
\hline Ma. wilsoni & 1 & 1 & 1 & 1 & 1 & 1 & 1 & 1 & 1 & 1 & - & 1 & 1 & 1 & 1 & 14 & 12 & 2 & 28 \\
\hline Ma.humeralis & - & 1 & 1 & - & 1 & - & 1 & 1 & - & - & - & 1 & 1 & 1 & 1 & 5 & 7 & 2 & 14 \\
\hline Ma.titillans & 1 & 1 & 1 & - & 1 & 1 & 1 & 1 & 1 & - & 1 & 1 & 1 & 1 & 1 & 14 & 11 & 2 & 27 \\
\hline Ps. cingulata & 1 & 1 & 1 & 1 & 1 & 1 & 1 & 1 & 1 & 1 & 1 & 1 & 1 & 1 & 1 & 21 & 13 & 2 & 36 \\
\hline Ps.albipes & 1 & 1 & 1 & 1 & - & 1 & 1 & 1 & 1 & 1 & 1 & 1 & 1 & 1 & 1 & 19 & 12 & 2 & 33 \\
\hline Tr. aranoides & 1 & 1 & - & - & - & 1 & - & 1 & - & 1 & - & 1 & 1 & 1 & 1 & - & 7 & 2 & 9 \\
\hline Tr. digitatum & 1 & 1 & 1 & - & 1 & 1 & 1 & 1 & 1 & 1 & - & 1 & - & 1 & 1 & 16 & 10 & 2 & 28 \\
\hline$T x$. amboinensis & 1 & 1 & 1 & 1 & 1 & 1 & 1 & 1 & 1 & 1 & 1 & 1 & 1 & 1 & 1 & 19 & 13 & 2 & 34 \\
\hline Ur. pulcherrima & 1 & 1 & 1 & - & 1 & 1 & 1 & 1 & 1 & 1 & 1 & 1 & 1 & 1 & 1 & 18 & 12 & 2 & 32 \\
\hline
\end{tabular}

Legend: Bold names represent sequenced mitogenomes. Disrupted or duplicated gene are represented by bold numbers. Unidentified gene are represented by - 
bioRxiv preprint doi: https://doi.org/10.1101/871145; this version posted December 10, 2019. The copyright holder for this preprint (which was not certified by peer review) is the author/funder, who has granted bioRxiv a license to display the preprint in perpetuity. It is made available

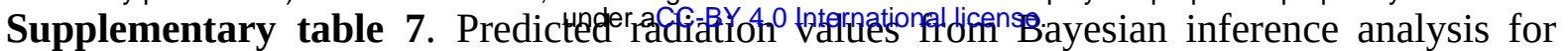
studied species. The HPD95\% values represents the confidence intervals for radiation between compared taxa.

\begin{tabular}{|c|c|c|c|}
\hline Node $^{1}$ & HPD 95\% & Median dating & Posterior probability \\
\hline A & 243.79-332.41 & 273.74 & 1 \\
\hline B & 145.88-232.95 & 182.75 & 1 \\
\hline $\mathrm{C}$ & $114.58-187.29$ & 145.83 & 1 \\
\hline $\mathrm{D}$ & $87.14-141.71$ & 110.73 & 1 \\
\hline E & $2.35-4.42$ & 3.27 & 1 \\
\hline $\mathrm{F}$ & 128.09-204.91 & 160.86 & 1 \\
\hline G & $1.43-2.81$ & 2.04 & 1 \\
\hline $\mathrm{H}$ & 117.92-195.06 & 151.36 & 0.5 \\
\hline I & $124.77-200.69$ & 157.02 & 0.49 \\
\hline $\mathrm{J}$ & 88.78-146.1 & 113.73 & 1 \\
\hline K & $66.37-115.22$ & 88.32 & 1 \\
\hline $\mathrm{L}$ & 66.31-109.73 & 85.29 & 1 \\
\hline M & 3.13-8.92 & 5.71 & 1 \\
\hline $\mathrm{N}$ & $101.87-168.21$ & 130.49 & 1 \\
\hline $\mathrm{O}$ & 81.02-132.17 & 102.87 & 1 \\
\hline $\mathrm{P}$ & $45.84-84.94$ & 63.25 & 1 \\
\hline $\mathrm{Q}$ & 74.02-121.02 & 94.04 & 1 \\
\hline $\mathrm{R}$ & $24.82-45.09$ & 33.9 & 1 \\
\hline S & $53.53-88.54$ & 68.94 & 1 \\
\hline $\mathrm{T}$ & 43.26-73.19 & 56.37 & 0.92 \\
\hline $\mathrm{U}$ & $79.07-135.87$ & 103.9 & 1 \\
\hline V & $16.73-28.91$ & 22.09 & 1 \\
\hline $\mathrm{x}$ & $7.78-16.85$ & 11.85 & 1 \\
\hline $\mathrm{Y}$ & $9.82-17.37$ & 13.15 & 1 \\
\hline Z & $15.05-26.45$ & 20.08 & 1 \\
\hline
\end{tabular}

${ }_{1}^{1}$ Nodes present in Figure 3 and Figure 4. 
bioRxiv preprint doi: https://doi.org/10.1101/871145; this version posted December 10, 2019. The copyright holder for this preprint (which was not certified by peer review) is the author/funder, who has granted bioRxiv a license to display the preprint in perpetuity. It is made available

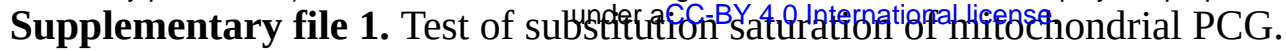

Analysis performed on all sites.

Testing whether the observed Iss is significantly lower than Iss.c.

IssSym is Iss.c assuming a symmetrical topology.

IssAsym is Iss.c assuming an asymmetrical topology.

Note: two-tailed tests are used.

\section{COI 1st+2nd codon positions:}

$\begin{array}{llllllll}\text { NumOTU Iss Iss.cSym } & \mathrm{T} & \mathrm{DF} & \mathrm{P} \text { Iss.cAsym } & \mathrm{T} & \mathrm{DF} & \mathrm{P}\end{array}$

\begin{tabular}{|c|c|c|c|c|}
\hline 4 & 0,119 & $0,82172,0611023$ & 0,0000 & $0,78968,777 \quad 1023 \quad 0,0000$ \\
\hline 8 & 0,120 & 0,789 64,934 1023 & 0,0000 & $0,68454,7151023 \quad 0,0000$ \\
\hline 16 & 0,124 & $0,77364,0191023$ & 0,0000 & $\begin{array}{llll}0,576 & 44,550 & 1023 & 0,0000\end{array}$ \\
\hline 32 & 0,147 & $0,750 \quad 59,2141023$ & 0,0000 & 0,445 29,334 $1023 \quad 0,0000$ \\
\hline
\end{tabular}

\section{COI 3rd codon positions:}

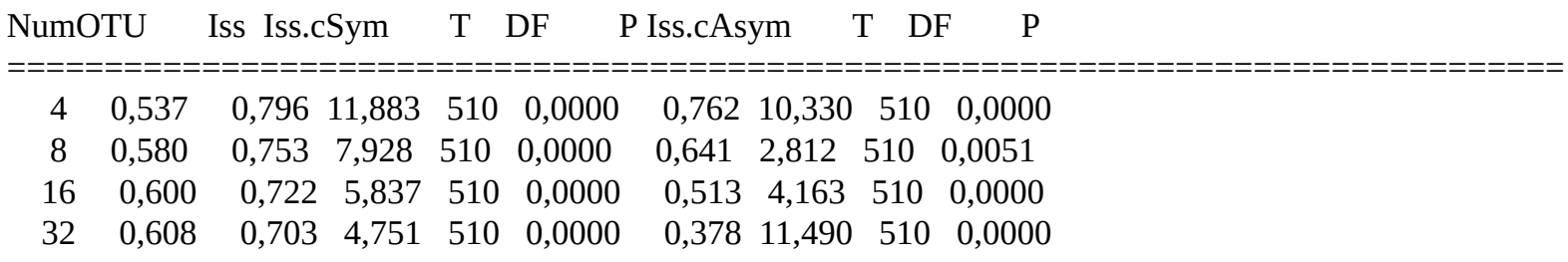

ND1 1st+2nd codon positions:

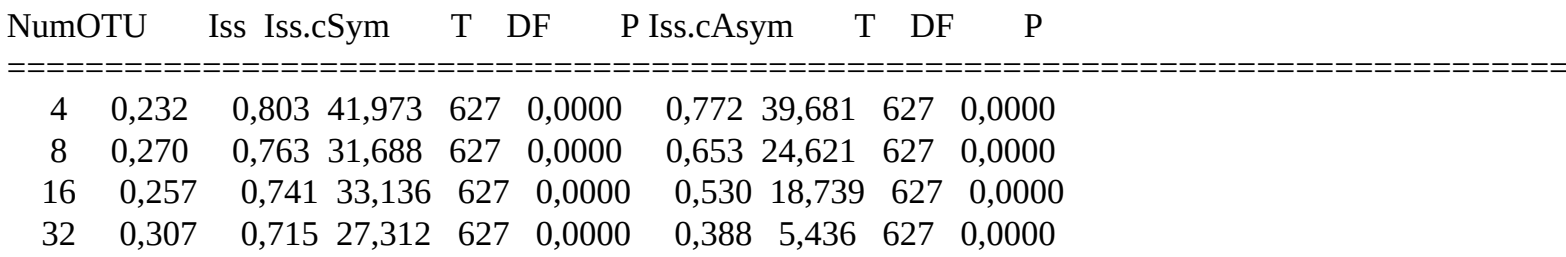

\section{ND1 3rd codon positions:}

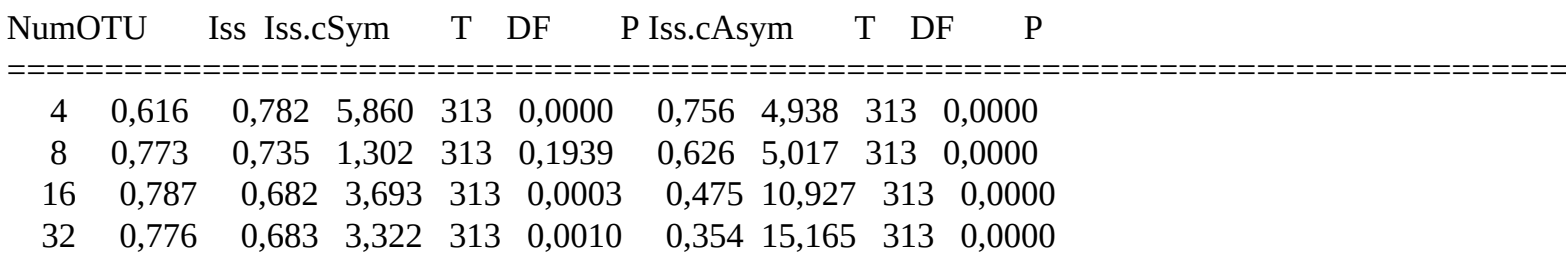

\section{ND2 1st+2nd codon positions:}

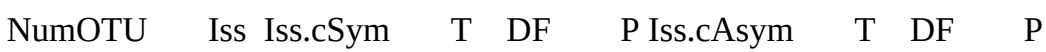

\begin{tabular}{|c|c|c|c|c|c|}
\hline 4 & 0,462 & $0,80619,700$ & 683 & 0,0000 & $0,775 \quad 17,927 \quad 683 \quad 0,0000$ \\
\hline 8 & 0,505 & $0,76814,386$ & 683 & 0,0000 & $0,658 \quad 8,401 \quad 683 \quad 0,0000$ \\
\hline 16 & 0,505 & $0,74713,360$ & 683 & 0,0000 & $\begin{array}{llll}0,538 & 1,812 \quad 683 & 0,0704\end{array}$ \\
\hline 32 & 0,598 & $0,721 \quad 6,691$ & 683 & 0,0000 & 0,396 10,982 $683 \quad 0,0000$ \\
\hline
\end{tabular}


bioRxiv preprint doi: https://doi.org/10.1101/871145; this version posted December 10, 2019. The copyright holder for this preprint (which was not certified by peer review) is the author/funder, who has granted bioRxiv a license to display the preprint in perpetuity. It is made available under aCC-BY 4.0 International license.

ND2 3rd codon positions:

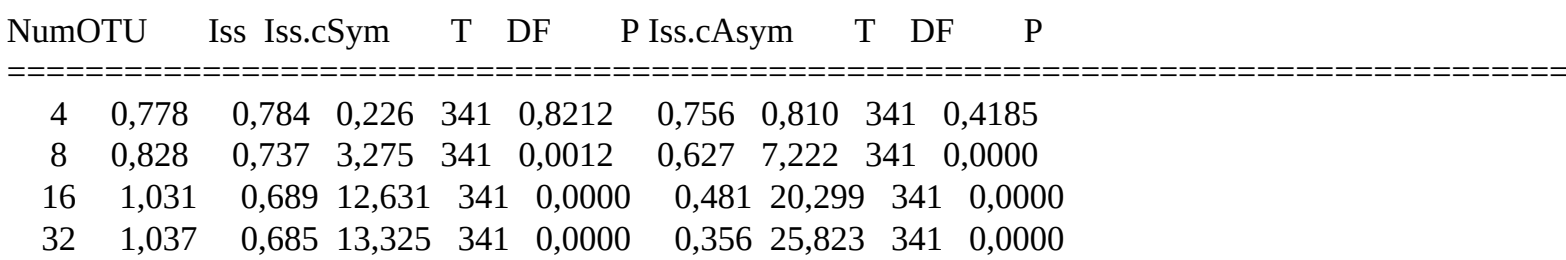

\section{ND3 1st+2nd codon positions:}

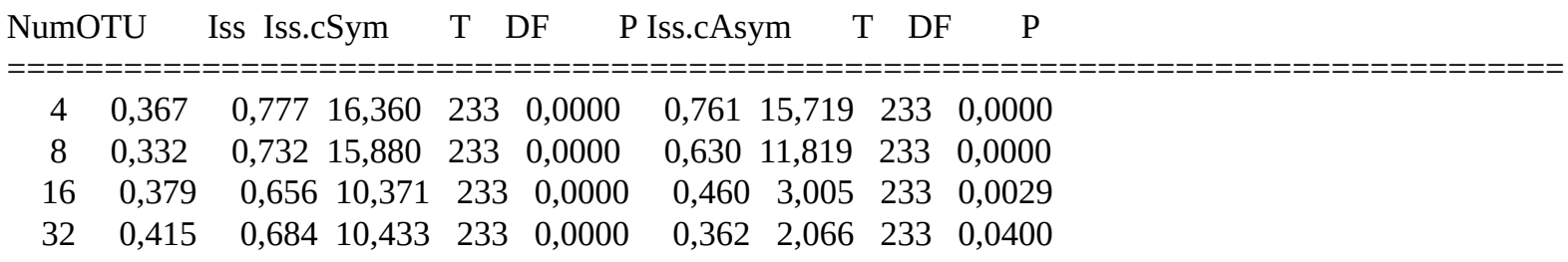

\section{ND3 3rd codon positions:}

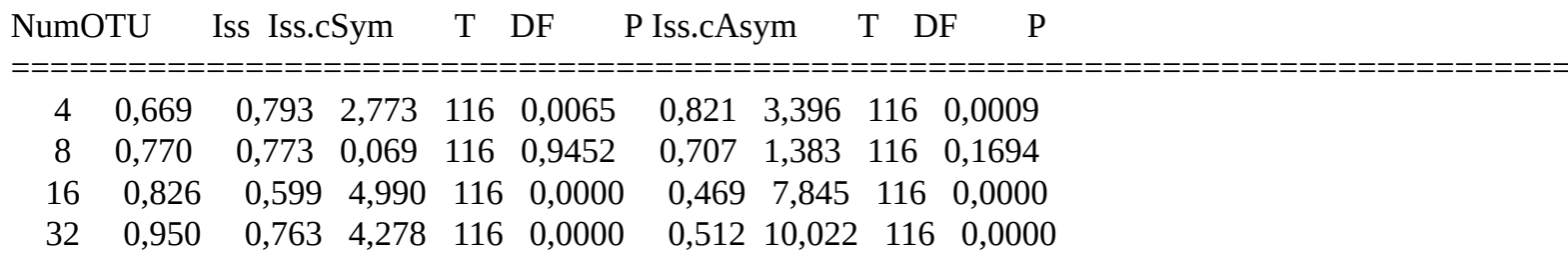

\section{ND4L 1st+2nd codon positions:}

NumOTU Iss Iss.cSym $\mathrm{T}$ DF $\quad$ P Iss.cAsym $\quad \mathrm{T} \quad \mathrm{DF} \quad \mathrm{P}$

\begin{tabular}{|c|c|c|c|c|c|c|c|}
\hline 4 & 0,330 & $0,780 \quad 17,564$ & 157 & 0,0000 & $0,784 \quad 17,747$ & 157 & 0,0000 \\
\hline 8 & 0,334 & $0,74514,305$ & 157 & 0,0000 & $0,65811,299$ & 157 & 0,0000 \\
\hline 16 & 0,349 & $0,62310,092$ & 157 & 0,0000 & $0,454 \quad 3,879$ & 157 & 0,0002 \\
\hline 32 & 0,432 & $0,71210,365$ & 157 & 0,0000 & $0,417 \quad 0,545$ & 157 & 0,5863 \\
\hline
\end{tabular}

\section{ND4L 3rd codon positions:}

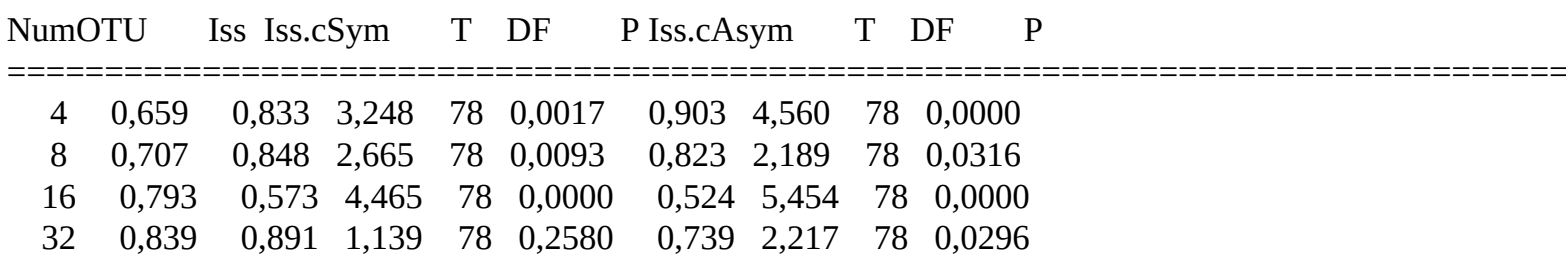

\section{ND4 1st+2nd codon positions:}

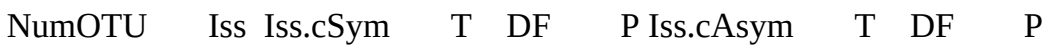

\begin{tabular}{|c|c|c|c|c|c|c|c|}
\hline 4 & 0,344 & 0,816 31,298 & 895 & 0,0000 & 0,785 29,198 & 895 & 0,0000 \\
\hline 8 & 0,357 & $0,782 \quad 24,785$ & 895 & 0,0000 & $0,67518,555$ & 895 & 0,000 \\
\hline 16 & 0,402 & $\begin{array}{lll}0,765 & 18,447\end{array}$ & 895 & 0,0000 & $0,563 \quad 8,178$ & 895 & 0,0000 \\
\hline
\end{tabular}


bioRxiv preprint doi: https://doi.org/10.1101/871145; this version posted December 10, 2019. The copyright holder for this preprint (which was not certified by peer review) is the author/funder, who has granted bioRxiv a license to display the preprint in perpetuity. It is made available

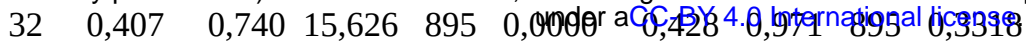

\section{ND4 3rd codon positions:}

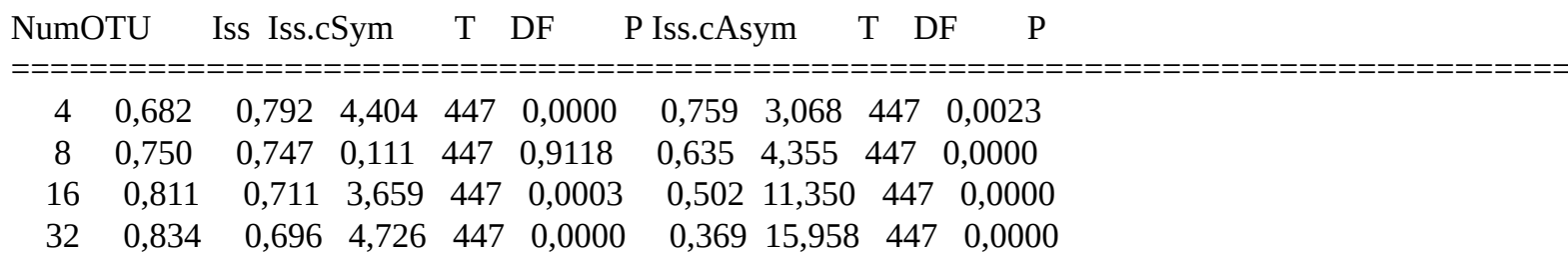

\section{ND5 1st+2nd codon positions:}

NumOTU Iss Iss.cSym $\quad \mathrm{T}$ DF $\quad$ P Iss.cAsym $\quad \mathrm{T} \quad \mathrm{DF} \quad \mathrm{P}$

\begin{tabular}{|c|c|c|c|c|c|}
\hline 4 & 0,390 & $0,826 \quad 28,4581161$ & 0,0000 & $0,79426,3721161$ & 0,0000 \\
\hline 8 & 0,375 & 0,796 23,303 1161 & 0,0000 & 0,692 17,559 1161 & 0,0000 \\
\hline 16 & 0,413 & $0,78017,2441161$ & 0,0000 & $0,587 \quad 8,1941161$ & 0,0000 \\
\hline 32 & 0,473 & $\begin{array}{lll}0,758 & 11,503 & 1161\end{array}$ & 0,0000 & $0,461 \quad 0,4521161$ & 0,6514 \\
\hline
\end{tabular}

\section{ND5 3rd codon positions:}

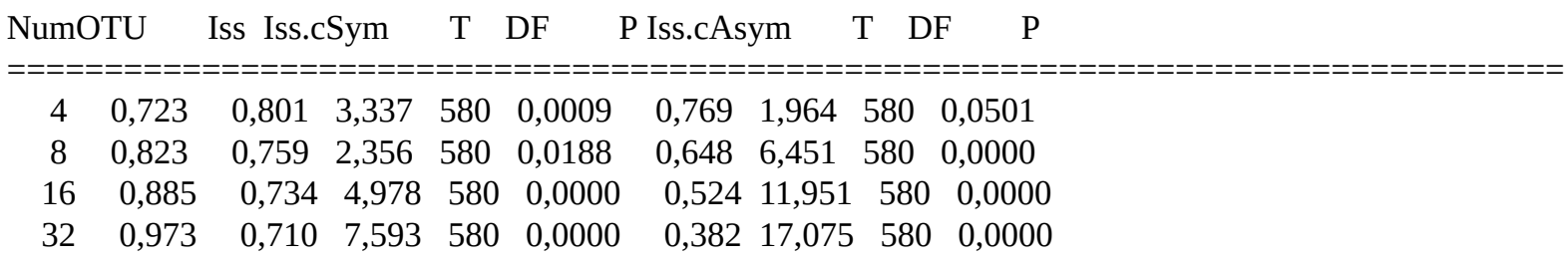

\section{ND6 1st+2nd codon positions:}

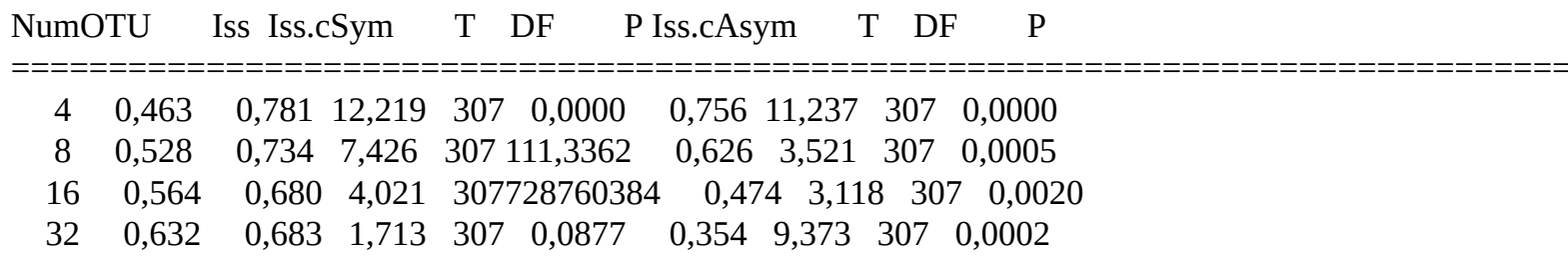

\section{ND6 3rd codon positions:}

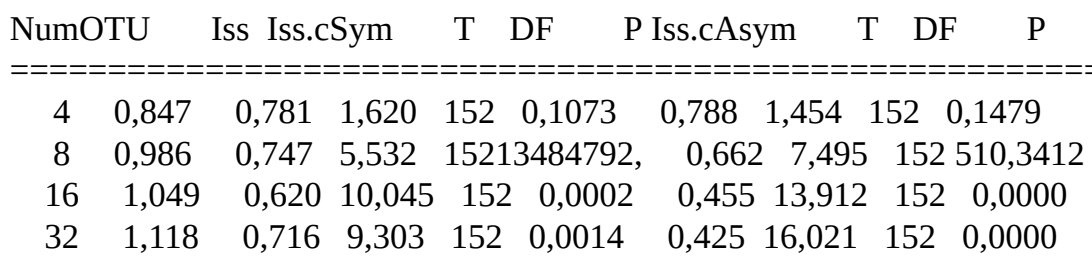

Interpretation of results:

Significant Difference

Yes No

Iss $<$ Iss.c Little
saturation $\begin{gathered}\text { Substantial } \\ \text { saturation }\end{gathered}$


bioRxiv preprint doi: https://doi.org/10.1101/871145; this version posted December 10, 2019. The copyright holder for this preprint (which was not certified by peer review) is the author/funder, who has granted bioRxiv a license to display the preprint in perpetuity. It is made available

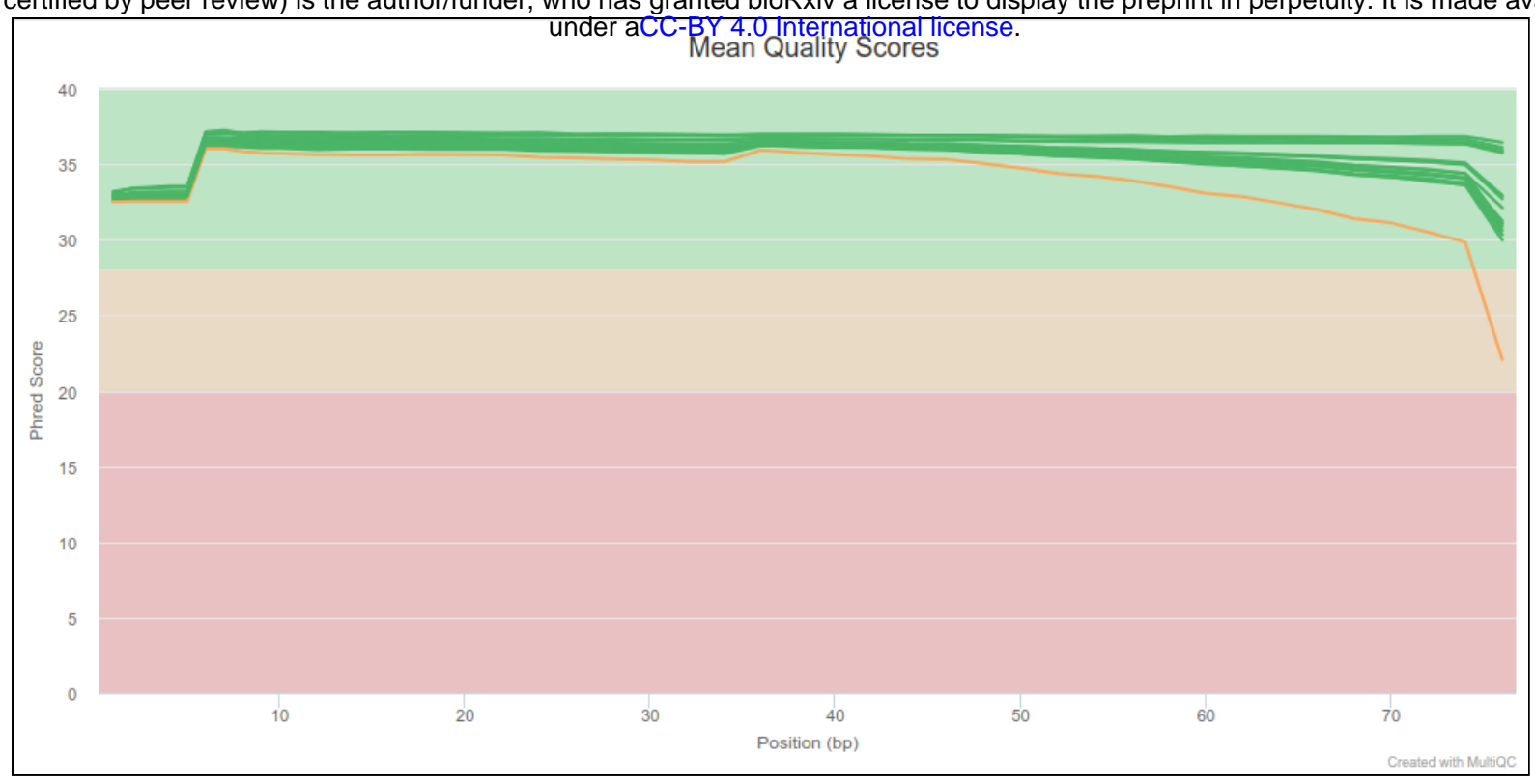

Supplementary figure 1. Quality of raw reads generated from mosquito samples. Figure generated from FasqQC results and summarized by MultiQC tool. The yellow line represents results from Cq. albicosta reads and green lines represent the remaining species. 
bioRxiv preprint doi: https://doi.org/10.1101/871145; this version posted December 10, 2019. The copyright holder for this preprint (which was not certified by peer review) is the author/funder, who has granted bioRxiv a license to display the preprint in perpetuity. It is made available Complete nucleotide mitogenome alignment sequences
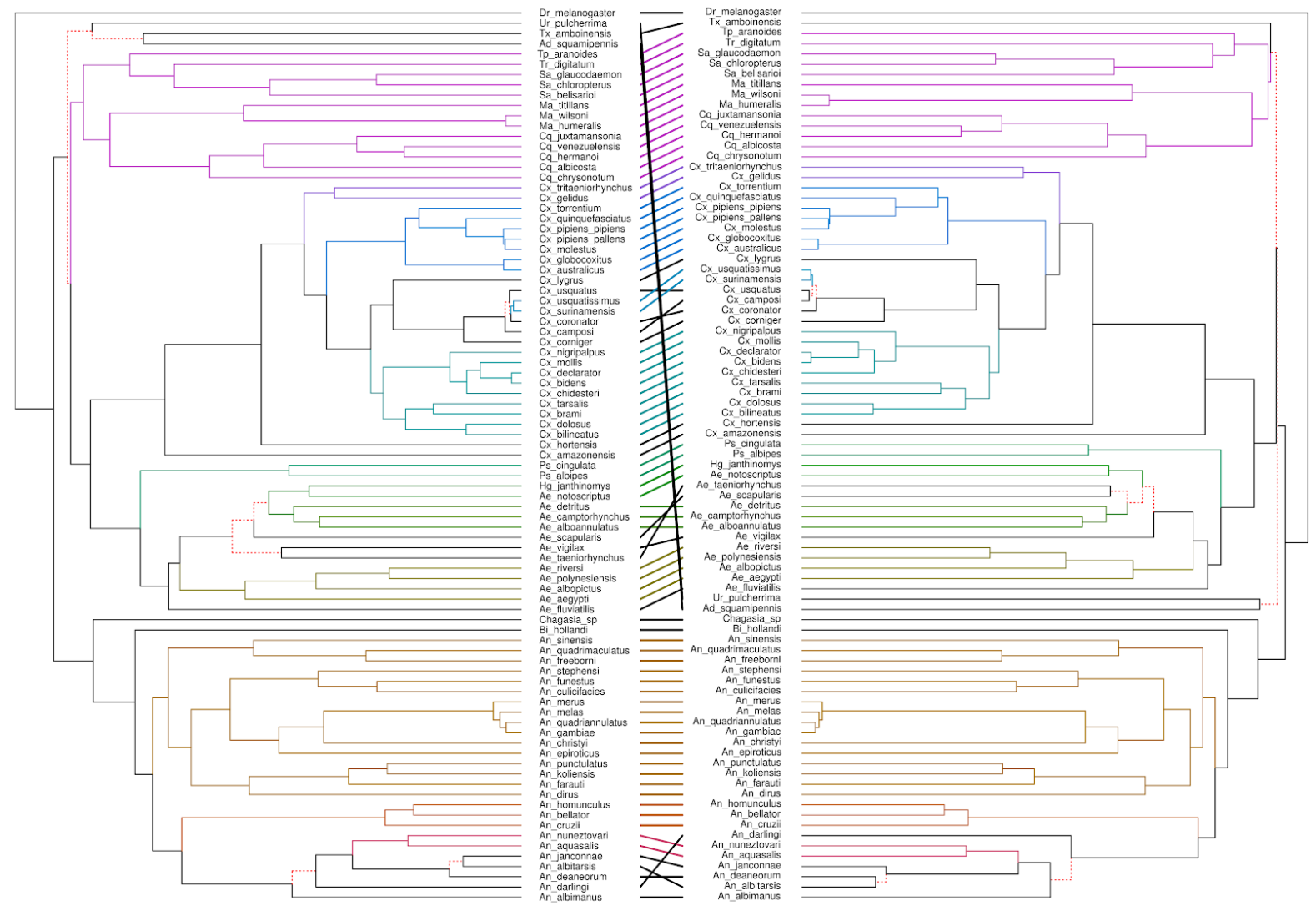

Supplementary figure 2. Comparative dendrogram topologies of trees obtained from different approaches using complete nucleotide mitogenomes and PCG with codon partition in the BEAST analysis. Dashed red lines show the branches that were different between the approaches used. 
bioRxiv preprint doi: https://doi.org/10.1101/871145; this version posted December 10, 2019. The copyright holder for this preprint (which was not certified by peer review) is the author/funder, who has granted bioRxiv a license to display the preprint in perpetuity. It is made available under aCC-BY 4.0 International license. sequences Partitioned predicted amino acid sequences
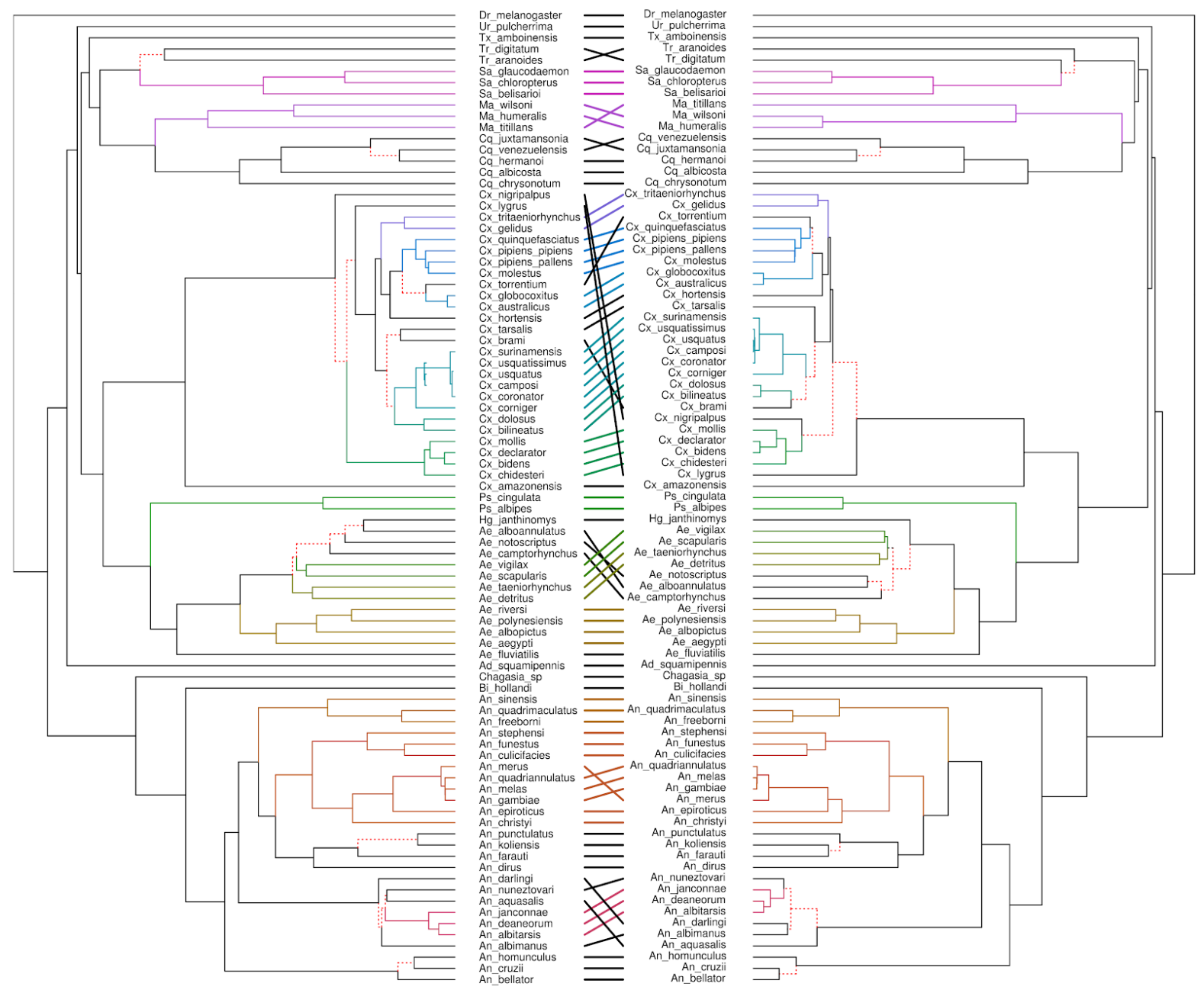

Supplementary figure 3. Comparative dendrogram topologies of trees obtained from different approaches using concatenated predicted amino acid sequences and partitioned predicted amino acid sequences in the BEAST analysis. Dashed red lines show the branches that were different between the approaches used. 
bioRxiv preprint doi: https://doi.org/10.1101/871145; this version posted December 10, 2019. The copyright holder for this preprint (which was not certified by peer review) is the author/funder, who has granted bioRxiv a license to display the preprint in perpetuity. It is made available

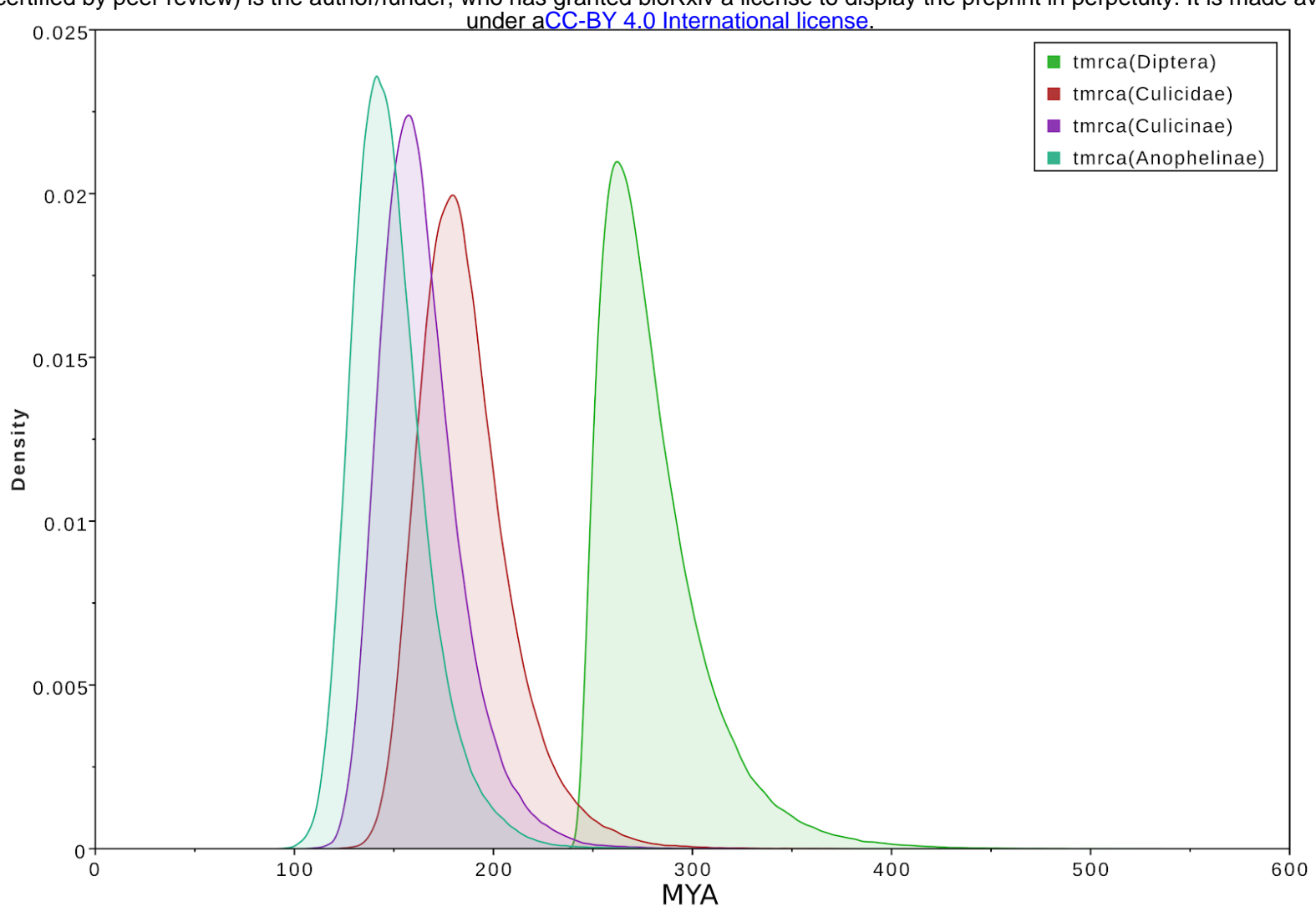

Supplementary figure 4. Density plot showing the 95\% posterior distribution of ancestors time estimate based on the alignment of partitioned mitochondrial PCG with codon partition. 
bioRxiv preprint doi: https://doi.org/10.1101/871145; this version posted December 10, 2019. The copyright holder for this preprint (which was not certified by peer review) is the author/funder, who has granted bioRxiv a license to display the preprint in perpetuity. It is made available

References:

1. Krzemiński, W., Krzemińska, E. \& Papier, F. Grauvogelia arzvilleriana sp. n. - the oldest Diptera species (Lower/Middle Triassic of France). Acta Zool. Cracov. 37, 95-99 (1994).

2. Borkent, A. \& Grimaldi, D. A. The Earliest Fossil Mosquito (Diptera: Culicidae), in Mid-Cretaceous Burmese Amber. Ann. Entomol. Soc. Am 97, 882-888 (2004).

3. Poinar, G. O., Zavortink, T. J., Pike, T. \& Johnston, P. a. Paleoculicis minutus ( Diptera: Culicidae ) n . gen ., n . sp ., from Cretaceous Canadian amber, with a summary of described fossil mosquitoes. Acta Geol. Hisp. 35, 119-128 (1999).

4. Zavortink, T. J. \& Poinar, G. O. Anopheles (Nyssorhynchus) dominicanus sp. n. (Diptera: Culicidae) from Dominican Amber. Ann. Entomol. Soc. Am. 93, 1230-1235 (2000). 